\title{
APPLICATION OF THE REDUCED I- $V$ BLAESSER'S CHARACTERISTICS IN PREDICTING PV MODULES AND CELLS CONVERSION EFFICIENCY IN MEDIUM AND HIGH INSOLATION CONDITIONS
}

\author{
UŻYCIE ZREDUKOWANYCH CHARAKTERYSTYK I- $V$ BLAESSERA \\ W PROGNOZOWANIU EFEKTYWNOŚCI KONWERSJI PV \\ W WARUNKACH ŚREDNICH I WYSOKICH NASŁONECZNIEŃ
}

\begin{abstract}
The article presents theoretical foundations of application of the reduced $I-V$ Blaesser's characteristics in predicting a photovoltaic cell/module (PV) efficiency, together with calculation procedures. A detailed analysis of the error of this transformation method of characteristics was carried out. Its practical application in predicting efficiency of operation of various PV cells and modules in medium and high insulation conditions was demonstrated. The practical suitability of the presented method in early detection of ageing phenomena, such as, for example, absorber degradation taking place in PV modules, was demonstrated. The article was prepared on the basis of the results of testing five different PV modules with various constructions, made of different materials and absorbers, such as: c-Si, mc-Si, CIS, a-Si_SJ, a-Si_TJ. The used measurement data were collected during the 16-year period of the experimental PV modules testing system operation in Opole University, equipped with a data acquisition system.
\end{abstract}

Keywords: photovoltaic conversion, PV cells/modules quality assessment, PV cells/modules degradation, PV cells/modules reduced I-U Blaesser's characteristics

The presented article is the second one in the series on non-standard application of commonly known calculation models and procedures in PV measuring. The first one titled: The use of two-diode substitute model in predicting the efficiency of PV conversion in low solar conditions [1] - regarded the non-standard application of a two-diode model in assessment of operation quality, including suitability for work in very low and low insulation conditions and in simple assessment of PV cells and modules degradation level. The second - currently presented, regards the application of standardised Blaesser's characteristics in assessment of construction and material degradation of cells and modules, in the medium and high insolation conditions. Similarly to the first, it was written in the form of a guide to the above mentioned studies, with detailed introduction and comment sections.

\footnotetext{
${ }^{1}$ Division of Physicochemical Research, University of Opole, ul. kard. B. Kominka 6, 45-032 Opole, Poland, phone +48 7745389 76, fax +48 7745591 49, email: maria.waclawek@uni.opole.pl, mrajfur@o2.pl

Corresponding author: trodziewicz@wp.pl
} 


\section{Introduction}

In order to assess technical condition of operating PV modules and the degree of degradation of their construction (e.g. absorber), it is necessary to compare their parameters in reference to always the same environment conditions defined in the IEC-60 904-3 standard [2], as so-called Standard Test Conditions (STC). These conditions cannot be maintained in most of the carried out measurements. The conditions included in the norm IEC-60 904-3 demand presentation of the obtained results of PV cells and modules at: PV cells temperature $T_{C}=25 \pm 2^{\circ} \mathrm{C}$, intensity of the falling solar radiation $G_{P O A}=1000 \mathrm{~W} / \mathrm{m}^{2}$ and spectral distribution of AM 1.5 type. Meeting these conditions for the measurements taken in external conditions may be very problematic. Therefore it becomes necessary to apply the mathematical conversion procedures, which enable converting individual I-V characteristic points of PV cells/modules from measurements other than STC to the values, which can be obtained in STC. A correction of the measured actual characteristics $I-V$ of PV cells and modules to the reference conditions defined as STC must be carried out. One of the four below presented correction methods for PV cells is used most frequently [3, 4]:

1) With the use of the procedures from the norm IEC-60 891 [5]:

$$
\begin{gathered}
I_{2}=I_{1}+I_{S C}\left[\frac{I_{S R}}{I_{M R}}-1\right]+\alpha \cdot\left(T_{2}-T_{1}\right), \\
U_{2}=U_{1}-R_{s}\left(I_{2}-I_{1}\right)-K \cdot I_{2}\left(T_{2}-T_{1}\right)+\beta \cdot\left(T_{2}-T_{1}\right) .
\end{gathered}
$$

2) Blaesser's method [6]:

$$
\begin{gathered}
I_{2}=I_{1} \frac{G_{2}}{G_{1}}\left(1+\alpha \cdot\left(T_{2}-T_{1}\right)\right), \\
U_{2}=U_{1}+\beta \cdot\left(T_{2}-T_{1}\right)+\frac{k_{B} T}{q} \ln \left(\frac{G_{2}}{G_{1}}\right)-R_{s} \cdot\left(I_{2}-I_{1}\right) .
\end{gathered}
$$

3) Method of Anderson [7]:

$$
\begin{gathered}
I_{2}=\left[\frac{G_{2}}{G_{1}}\right] \cdot \frac{I_{1}}{\left[1+\alpha\left(T_{2}-T_{1}\right)\right]}, \\
U_{2}=\frac{V_{1}}{\left[1+\beta\left(T_{2}-T_{1}\right)\right] \cdot\left[1+\frac{k T}{q} \cdot \ln \left(G_{1} / G_{2}\right)\right]} .
\end{gathered}
$$

4) Two-Exponential Model $[8,9]$ (analytic):

$$
I(U)=I_{p h}-I_{S 1}\left\{\exp \left(\frac{U+I \cdot R_{s}}{n_{1} \cdot U_{T}}\right)-1\right\}-I_{S 2}\left\{\exp \left(\frac{U+I \cdot R_{s}}{n_{2} \cdot U_{T}}\right)-1\right\}-\left(\frac{U+I \cdot R_{s}}{R_{s h}}\right),
$$

where: 


$$
\begin{gathered}
U_{T}=\frac{k T}{q}, I_{S 1} \propto T^{3} \cdot \exp \left(\frac{-\Delta W}{k T}\right), I_{S 2} \propto T^{2.5} \cdot \exp \left(\frac{-\Delta W}{2 k T}\right), \\
I_{p h 2}(G, T)=I_{p h 1} \cdot \frac{G_{2}}{G_{1}} \cdot \frac{1+\alpha \cdot\left(T_{2}-25^{\circ} C\right)}{1+\alpha \cdot\left(T_{1}-25^{\circ} C\right)} .
\end{gathered}
$$

Index 1 refers to the measured parameters of a cell characteristics, index 2 refers to the results obtained after the correction to the final cell temperature $T_{C}$ and radiation intensity G. $T_{2}-T_{1}$ is the corrected temperatures difference, $G_{2}-G_{1}$ is the corrected difference of radiation value.

The first three methods require a few parameters, such as short-circuit current temperature coefficient $\alpha$ and open circuit voltage $\beta$ as well as serial resistance $R_{s}$ of the analysed element. The procedure within IEC-60 891 standard uses the fourth parameter referred to as "K curve correction coefficient." Such parameters are not used in a two-diode model, but they are required in the curve simulation computer software $I-V[9]$. More information regarding the PV characteristics linearization and their temperatures corrections can be found in [10-15].

Summing up:

1) The above mentioned methods for characteristics correction to STC conditions can be applied only for the conversion not greater than [3]: $\Delta T_{C}= \pm(30, \max 40) \mathrm{K}-$ of a cell temperature and for $\Delta G= \pm 300 \mathrm{~W} / \mathrm{m}^{2}$ - of solar radiation intensity. Then, for the applied correction methods 1-3, a relative error of voltage measurement is, respectively: $\delta U_{O C} \cong 2 \%$ and $<2.5 \%$, for limit ranges of temperature correction, i.e. 30 and $40 \mathrm{~K}$. Whereas a relative error of current measurement: $\delta I_{S C} \cong 8 \%$ for the radiation correction range $\Delta G= \pm 300 \mathrm{~W} / \mathrm{m}^{2}$. In the case of the 4th correction method the obtained errors are greater and amount to: $\delta U_{O C} \cong 3$ at $\Delta T_{C}= \pm 30 \mathrm{~K}, \delta U_{O C} \cong 5.5$ at $\Delta T_{C}= \pm 40 \mathrm{~K}$ and $\delta I_{S C} \cong 14 \%$ at $\Delta G= \pm 300 \mathrm{~W} / \mathrm{m}^{2}$.

2) The application of characteristics correction methods to the STC operation conditions is quite troublesome in practical, engineering work. Irrespective of the applied method, it requires determining the actual values of coefficients and resistance. These coefficients change along with the progressing degradation of PV modules construction. Moreover, some of them, for example resistances $\left(R_{s}, R_{s h}\right)$ and a diode excellence coefficients $\left(n_{1}, n_{2}\right)[16,17]$ change their values along with the increase of a cell temperature and the values of falling radiation. More information regarding the influence of absorber degradation on the value of $n$ coefficient can be found in [18-21].

3) Considering tight restrictions regarding the possible range of corrections - their direct use in comparing/analysing $I-V$ characteristics of the modules, operating in a wide range of variability of conditions (i.e. high range of $T_{C}$ and $G$ values fluctuation) - is practically impossible. However, already in 1997 during the $14^{\text {th }}$ EPSEC in Barcelona, G. Blaesser presented a new method of comparison, based on the use of so called reduced $I-V$ characteristics of PV modules, which should be almost independent from meteorological conditions in the location where they operate [22].

\section{Blaesser's reduced $I-V$ characteristics of $P V$ modules}

The reduced current voltage $(I-V)$ characteristics of PV module is obtained from the ordinary form of $I-V$ characteristics, by normalisation of current $I$ to the value of short 
circuit current of a module $I_{S C}$ and voltage $U$ to the value of open circuit voltage $U_{O C}$ of a PV module. Therefore, it is a function of:

$$
\left\{\begin{array}{l}
i=f(v), \\
i=I / I_{S C}, \\
v=U / U_{O C} .
\end{array}\right.
$$

The measured (source/original) $I-V$ curve of a PV module is a set of pairs of values ("points") $(I, U)$, from the short circuit point $\left(I_{S C}, 0\right)$ to the open circuit point $\left(0, U_{O C}\right)$. These points form a curve on the plane $(I, U)$, which function graph $I=F(U)$ - is referred to as $I-V$ characteristics. As the reduced characteristics use the normalised values of $I / I_{S C}$ and $U / U_{O C}$, all characteristics are automatically rescaled to the range from 0 to 1 . This operation allows to locate all characteristics in one graph, irrespective of the atmospheric conditions present during measurement taking, and compare them.

Note: The basic limitation of the above mentioned procedure [22] regards comparison of the measured curves with characteristics extrapolated to STC, only with maintaining the minimum lighting level of modules $G_{P O A} \geq 600 \mathrm{~W} / \mathrm{m}^{2}$.

\section{Analysis of the method error in Blaesser's reduced $I-V$ characteristics}

\section{Theoretical analysis}

The method of Blaesser's reduced current voltage $(I-V)$ characteristics is based on translation of current $(I, 0)$ and voltage $(0, U)$ coordinates of the actual measurement points, using the simplified Blaesser's procedures, i.e. the expressions: (3) and (4). Then:

$$
\begin{gathered}
I_{2}\left(T_{2}, G_{2}\right)=I_{1}\left(T_{1}, G_{1}\right) \cdot \frac{G_{2}}{G_{1}}\left(1+\alpha \cdot\left(T_{2}-T_{1}\right)\right) \\
U_{2}\left(T_{2}, G_{2}\right)=U_{1}\left(T_{1}, G_{1}\right)+\underbrace{\beta \cdot\left(T_{2}-T_{1}\right)+N \frac{k_{B} T}{q} \ln \left(\frac{G_{2}}{G_{1}}\right)}_{D U(T, G)}-R_{s} \cdot\left(I_{2}-I_{1}\right)
\end{gathered}
$$

After simplifying and assuming that $I_{2}$ is a module current for $T_{C}=T_{2}$ and $G_{P O A}=G_{2}$, similarly to $I_{1}$ and to $U_{2}$ and $U_{1}$ we obtain:

$$
\begin{gathered}
I_{2}=I_{1} \cdot \frac{G_{2}}{G_{1}}\left(1+\alpha \cdot\left(T_{2}-T_{1}\right)\right) \\
U_{2}=U_{1}+D U-R_{s} \cdot\left(I_{2}-I_{1}\right)=U_{1}+D U+R_{s} \cdot\left(I_{1}-I_{2}\right)
\end{gathered}
$$

Analysis of the current coordinate translation function (11):

By translating $I_{S C 1}$ to the conditions $T_{2}$ and $G_{2}$ according to (11) and dividing both sides, we obtain: 


$$
\begin{gathered}
i_{2}=\frac{I_{2}}{I_{S C 2}}=\frac{I_{1}}{I_{S C 1}} \cdot \frac{\frac{G_{2}}{G_{1}}\left(1+\alpha \cdot\left(T_{2}-T_{1}\right)\right)}{\frac{G_{2}}{G_{1}}\left(1+\alpha \cdot\left(T_{2}-T_{1}\right)\right)}=\frac{I_{1}}{I_{S C 1}}=i_{1} \\
i_{2}=i_{1} \\
\frac{I_{2}}{I_{1}}=\frac{G_{2}}{G_{1}}(\underbrace{1+\alpha \cdot\left(T_{2}-T_{1}\right)}_{1 \gg \alpha \cdot\left(T_{2}-T_{1}\right)}) \approx \frac{G_{2}}{G_{1}} . \\
I_{2}=I_{1} \cdot \frac{G_{2}}{G_{2}}=I_{1} \cdot \frac{I_{S C 2}}{I_{S C 1}}
\end{gathered}
$$

Analysis of the voltage translation function (12):

Using the voltage translation function (12) and substituting for $U=U_{O C 1}$, we obtain:

$$
U_{O C 2}=U_{O C 1}+D U
$$

That means that the voltage translation value is:

$$
D U=U_{O C 2}-U_{O C 1}
$$

Introducing the definition of the reduced values of voltage translation and resistance $R_{s}$ of the formula:

$$
\begin{gathered}
D v=\frac{D U}{U_{O C 1}} \\
r_{s}=R_{s} \cdot \frac{I_{S C 1}}{U_{O C 1}}
\end{gathered}
$$

the function of voltage coordinate translation takes the form:

$$
\begin{gathered}
v_{2}=\frac{U_{2}}{U_{O C 2}}=\frac{U_{1}+D U+R_{s} \cdot\left(I_{1}-I_{2}\right)}{U_{O C 1}+D U}=\frac{\underbrace{U_{1}}_{v_{1}}}{U_{O C 1}} \cdot \frac{1+\frac{D U}{U_{1}}+R_{s} \frac{I_{1}-I_{2}}{U_{1}}}{1+\underbrace{\frac{D U}{U_{O C 1}}}_{D v}} \\
\varepsilon=v_{2}-v_{1}
\end{gathered}
$$

where $\varepsilon$ - means a voltage translation error and defines inaccuracy of transformation at voltage axis.

A voltage translation error function ,, $\mathcal{E}^{\prime \prime}$ : 


$$
\begin{aligned}
& \varepsilon=v_{2}-v_{1}=v_{1} \cdot \frac{1+\frac{D U}{U_{1}}+R_{s} \frac{I_{1}-I_{2}}{U_{1}}}{1+D v}-v_{1}=\frac{v_{1}}{1+D v} \cdot\left[1+\frac{D U}{U_{1}}+R_{s} \frac{I_{1}-I_{2}}{U_{1}}-1-D v\right]= \\
& =\frac{v_{1}}{1+D v} \cdot[\underbrace{\frac{D U}{U_{1}}}_{\substack{U_{1}=v \cdot U_{O C 1} \\
D v=\frac{D U}{U_{O C 1}}}}+\underbrace{R_{s} \frac{I_{1}-I_{2}}{U_{1}}}_{r_{s}=R_{s} \cdot \frac{I_{S C 1}}{U_{O C 1}}}-D v]=\frac{v_{1}}{1+D v} \cdot[\frac{D v}{v_{1}}+\underbrace{\frac{r_{s} \cdot U_{O C 1}}{I_{S C 1} \cdot U_{1}}}_{\substack{i_{1}=I_{1} / I_{S C 1} \\
v_{1}=U_{1} / U_{O C 1}}} \cdot I_{1} \cdot(1-\underbrace{\frac{I_{2}}{I_{2} / I_{1}=G_{2} / G_{1}}})-D v]= \\
& =\frac{v_{1}}{1+D v} \cdot\left[\frac{D v}{v_{1}}+\frac{r_{s} \cdot i_{1}}{v_{1}} \cdot\left(1-\frac{G_{2}}{G_{1}}\right)-D v\right]=\frac{1}{1+D v} \cdot\left[D v+r_{s} \cdot i_{1} \cdot\left(1-\frac{G_{2}}{G_{1}}\right)-v_{1} \cdot D v\right] \\
& \varepsilon=\frac{1}{1+D v} \cdot\left[D v \cdot\left(1-v_{1}\right)+r_{s} \cdot i_{1} \cdot\left(1-\frac{G_{2}}{G_{1}}\right)\right]
\end{aligned}
$$

Summing up:

Comparing the expressions (13) and (20) we obtain translation functions of points coordinates of the Blaesser's reduced characteristics (23):

$$
\left\{\begin{array}{l}
i_{1}=i_{2} \\
v_{2}=v_{1}+\varepsilon
\end{array}\right.
$$

Expression of the translation error function of Blaesser's reduced characteristics

Using the definition (8) and the function of translation of points coordinates of Blaesser's reduced characteristics (23) one can notice that the translation changes the reduced characteristics:

$$
\begin{gathered}
i_{1}=f\left(v_{1}\right) \\
\text { into: } i_{2}=f\left(v_{2}\right)=f\left(v_{1}+\varepsilon\right)=f\left(v_{1}\right)+\frac{d}{d v_{1}} f\left(v_{1}\right) \cdot \mathcal{E}
\end{gathered}
$$

Then, the absolute and relative error of the translation method takes the form, respectively:

$$
\begin{gathered}
\Delta i=\underbrace{f\left(v_{1}+\varepsilon\right)}_{i_{2}}-\underbrace{f\left(v_{1}\right)}_{i_{1}}=\frac{d}{d v_{1}} f\left(v_{1}\right) \cdot \varepsilon \\
\delta_{i}[\%]=100 \frac{i_{2}-i_{1}}{i_{1}}=100 \frac{1}{i_{1}} \frac{d}{d v_{1}} f\left(v_{1}\right) \cdot \mathcal{\varepsilon}
\end{gathered}
$$

\section{Practical estimate of the method error in Blaesser's reduced I-V characteristics}

Analysis with the use of one-diode substitute PV model

The form of a one-diode substitute PV module is described by the expression (28): 


$$
I=\underbrace{I_{p h}}_{\approx I_{S C}}-I_{0} \cdot\left\{\exp \frac{\left(U+R_{s} \cdot I\right) / N}{n \cdot U_{T}}-1\right\}-\frac{U+R_{s} \cdot I}{R_{s h}}
$$

where: $U_{T}=k T / q$ - free enthalpy (thermodynamic potential) of $26 \mathrm{mV}$ for silicon at temperature $300 \mathrm{~K}, n$ - diode quality coefficient in a one-diode model, $N$ - number of cells in a PV module.

Due to the fact that in Blaesser's translation method, the parallel resistance of a cell/module is not taken into consideration, i.e. it is assumed that $R_{s h}=\infty$, the expression (28) is simplified to the form (29):

$$
I=I_{S C}-I_{0} \cdot\left\{\exp \frac{\left(U+R_{s} \cdot I\right) / N}{n \cdot U_{T}}-1\right\}
$$

Then, the function $F(U)$ for the conditions $T_{1}$ and $G_{1}$ assumes the form:

$$
\begin{gathered}
I_{1}=I_{S C 1}-I_{0} \cdot\left\{\exp \frac{\left(U_{1}+R_{s} \cdot I_{1}\right) / N}{n \cdot U_{T}}-1\right\} \text {, dividing sides by } I_{S C 1} \text { we obtain: } \\
i_{1}=1-\frac{I_{0}}{I_{S C 1}} \cdot\{\underbrace{\exp \frac{v_{1} U_{O C 1}+R_{s} \cdot i_{1} I_{S C 1}}{n \cdot N \cdot U_{T}}}_{\substack{I_{1}=i_{1} I_{S C 1} \\
U_{1}=v_{1} U O C 1 \\
r_{s} R_{S} I_{S C 1} / U_{O C 1}}}-1\}=1-\frac{I_{0}}{I_{S C 1}} \cdot\left\{\exp \frac{v_{1} U_{O C 1}+r_{s} \cdot i_{1} U_{O C 1}}{n \cdot N \cdot U_{T}}-1\right\}= \\
=1-\frac{I_{0}}{I_{S C 1}} \cdot\left\{\exp \left(\frac{U_{O C 1}}{n \cdot N \cdot U_{T}}\left(v_{1}+r_{s} i_{1}\right)\right)-1\right\}
\end{gathered}
$$

Considering that:

$$
\begin{aligned}
& \left.\begin{array}{l}
U_{O C 1}=n \cdot N \cdot U_{T} \cdot \ln \left(1+\frac{I_{S C 1}}{I_{0}}\right) \\
1<\frac{I_{S C 1}}{I_{0}},
\end{array}\right\} \approx n \cdot N \cdot U_{T} \cdot \ln \left(\frac{I_{S C 1}}{I_{0}}\right) \\
& \frac{U_{O C 1}}{n N U_{T}}=\ln \left(\frac{I_{S C 1}}{I_{0}}\right) \Rightarrow \frac{I_{0}}{I_{S C 1}}=e^{-\frac{U_{O C 1}}{n N U_{T}}}
\end{aligned}
$$

then, Blaesser's reduced characteristics function assumes the form:

$$
i_{1}=f\left(v_{1}\right)=1-e^{\frac{U_{O C 1}}{n N U_{T}}\left(v_{1}+r_{s} i_{1}-1\right)}+e^{-\frac{U_{O C 1}}{n N U_{T}}},
$$

and in the case of a reduced characteristics with translation to the conditions $T_{2}$ and $G_{2}$ :

$$
i_{2}=f\left(v_{2}\right)=f\left(v_{1}+\varepsilon\right)=1-e^{\frac{U_{O C 1}}{n N U_{T}}\left(v_{1}+\mathcal{E}+r_{s} i_{1}-1\right)}+e^{-\frac{U_{O C 1}}{n N U_{T}}} .
$$


In this case, using (26) and (33) and (34), absolute error of Blaesser's reduced characteristics translation assumes the form:

$$
\begin{aligned}
& \Delta i=\underbrace{f\left(v_{1}+\varepsilon\right)}_{i_{2}}-\underbrace{f\left(v_{1}\right)}_{i_{1}}=e^{\frac{U_{O C 1}}{n N U_{T}}\left(v_{1}+r_{s} i_{1}-1\right)}-e^{\frac{U_{O C 1}}{n N U_{T}}\left(v_{1}+\mathcal{E}+r_{s} i_{1}-1\right)} \\
& \Delta i=\frac{d}{d v_{1}} f\left(v_{1}\right) \cdot \mathcal{E}=\frac{d}{d v_{1}}\left(1-e^{\frac{U_{O C 1}}{n N U_{T}}\left(v_{1}+r_{s} i_{1}-1\right)}+e^{-\frac{U_{O C 1}}{n N U_{T}}}\right) \cdot \mathcal{E}
\end{aligned}
$$

Relative error is determined in line with (27), having determined (35) or (36) before. Whereas a simplified form of absolute error of translation of reduced characteristics, for the case when $R_{s}=0$ (i.e. $r_{s}=0$ ), is presented by the relation (37):

$$
\Delta i=e^{\frac{U_{O C 1}}{n N U_{T}}\left(v_{1}-1\right)}-e^{\frac{U_{O C 1}}{n N U_{T}}\left(v_{1}+\varepsilon-1\right)}
$$

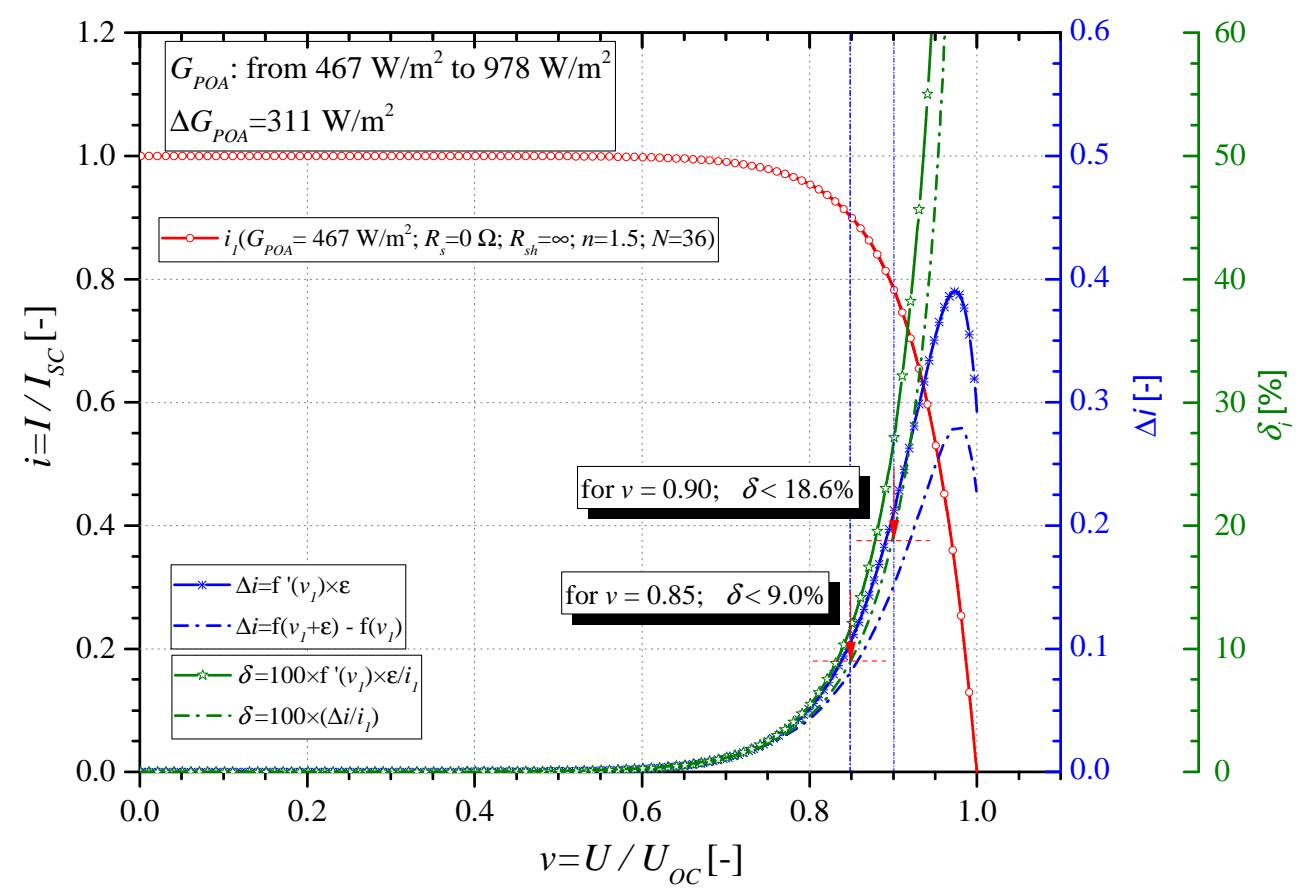

Fig. 1. The graph of normalised I-V characteristics, according to Blaesser's method, and the function sequence of absolute and relative errors, determined according to (35) and (36) for the case of translation from 467 to $978 \mathrm{~W} / \mathrm{m}^{2}$ lighting level

In Figure 1 the following curves are presented: red - normalised $I$ - $V$ characteristics of a module built of 36 ideal cells connected in series, with zero resistance $R_{s}=0 \Omega$, without parallel resistance (i.e. $R_{s h}=\infty \Omega$ and for the assumed diode excellence coefficient in one-diode substitute model $n=1.5$; blue - value of absolute error, determined: according to (36) - curve with asterisk and according to (35) - dashed curve; green - value of absolute 
error, determined according to (27) for the previously determined relative errors, according to (36) and (35). The analysis of Figure 1 brings the following observations:

a) The ideal $I-V$ characteristics of the module as well as its normalised characteristics has almost zero inclination in the range of voltages $v<0.6\left(R_{s h}=\infty\right)$ and a very sharply falling side (large inclination) of characteristics for voltages close to $v \cong 1$. In consequence, we see almost zero value of translation errors in voltages range $v<0.6$ and a very fast increase of errors values after exceeding so called " $I$ - $V$ characteristics elbow" and getting closer to the value $v$ to 1 . That is, after exceeding $v>0.9$ (the effect of a very high value of derivative in this area of the curve).

b) The results obtained from the relation (36) and (35) are basically comparable. The obtained differences result from the fact that the derivative from the relation (36) in direct vicinity $v \rightarrow 1$ heads to $\infty$ for $R_{s}=0 \Omega$ and distorts the actual error value, which does not take place in the case of actual modules, i.e. when their $R_{s}>0$.

c) Despite using a considerable simplification of a module model, the obtained relative error result $\delta_{I}$ of translation for $\Delta G_{P O A}=311 \mathrm{~W} / \mathrm{m}^{2}$ amounting to $\delta_{i}(v=0.85)=9 \%$, is comparable to the actual results when using characteristics correction procedures with the use of translation from methods from (1) to (3), which is within the range $\delta I_{S C} \cong 8 \%[3]$.

d) In the analyses, the reduced voltage value $\boldsymbol{v}=\mathbf{0 . 8 5}$, as the reference voltage was assumed - because in the actual cells/modules, the value $(0.8-0.85) \cdot U_{O C} \cong U_{m}$ - is the engineer's method for fast estimation of the maximum power point voltage value, from the value $U_{O C}[23]$.

Summing up:

1. The expressions from (33) to (36) have entangled forms. The only method for plotting and solving them is the use of numerical solutions or specialist software, e.g. Mathematica or similar.

2. The described method of determining the error, introduced by the idea of Blaesser's reduced characteristics translation method, has its weak spots:

a) it does not take into consideration the occurrence of modules parallel resistance $\left(R_{s h}\right)$, which influences the changes of characteristics in the range of low lighting levels,

b) the identified error $\varepsilon$ - translation in voltage axis, does not differentiate between the error originating from the increase of cells temperature $T_{C}$ in the module and the error from the increase of lighting level $G$ (see Fig. 10). These factors have contradictory influence on the increases of output voltages in modules.

c) The used parameters of modules, such as $n, R_{s}$, do not have fixed values but change, along with the increase of $T_{C}$ of cells in a module and with the change of its lighting level, which causes additional errors. They also change along with the process of a module construction ageing/degradation.

d) Determining $I-V$ characteristics of modules for different values of radiation intensity $G_{P O A}$ in open space conditions, leads in practice to taking measurements of $I-V$ characteristics of modules for various spectral distributions of solar radiation. The following values are different: Air Mass $(A M)$, Average Values of Photon Energy $(A P E)$ and the contents of the useful fraction $(U F)$ of the solar spectrum. 
e) Comparing Blaesser's reduced characteristics for different values of radiation intensity $G$, without taking into consideration the changes of ambient temperature $\left(T_{a m b}\right)$ involves the comparison of the obtained, normalised PV modules characteristics operating at different levels of adjustment of spectral sensitivity characteristics to the spectral distribution of the solar radiation.

3. The analysis of the remark from point 2 suggests that it is actually very difficult to filter out the external factors, influencing errors of translation of Blaesser's reduced characteristics, in order to determine the error of the method when applying the above mentioned function.

\section{Analysis with the use of a PV cell simulator}

A program simulator of a silicon PV cell made for laboratory-didactic classes was used for further analysis. The input data were generated numeric tables of AM1.5G spectrum, according to the procedures included in the SMART2 [24] application - relevant to the spectrum reference distribution from the norm IEC 60904-3. The module consisting of 32 $(N=32)$ silicon cells connected in series, in which a single $I-V$ characteristics was generated by the above mentioned simulator. Thus the characteristics is generated by linear scaling (x32) of voltage values from a single PV module cell characteristics.

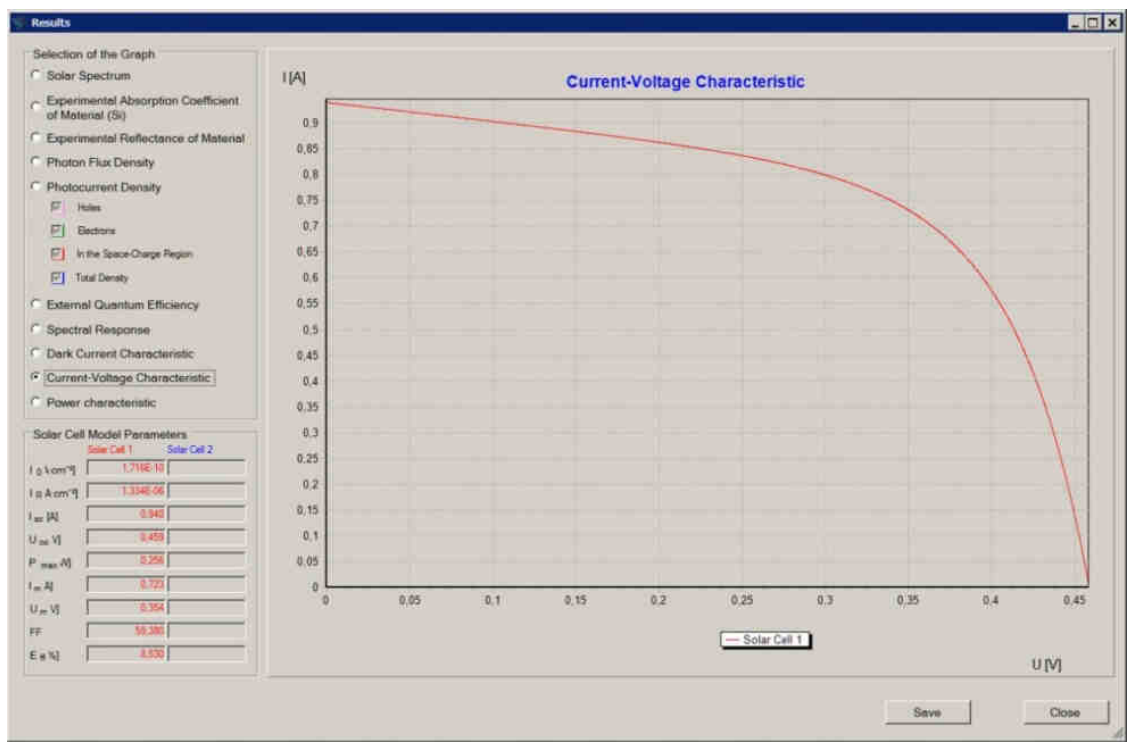

Fig. 2. The result window of the PV silicon cell operation simulator called "Silicon Solar Cells"

The simulator was prepared according to the procedures describe in $[25,26]$. Table 1 presents the cell material parameters taken from [25], required for the simulator operation. The simulation was carried out for two leakage resistance values $R_{s h}=276 \Omega$, and $100,000 \Omega$ - further marked in figure as $R_{s h}=\infty \Omega$, i.e. without leakage resistance. The assumed value of the module serial resistance $R_{s}=0.37 \Omega$. The application contains numerical procedures for plotting and solving implicit functions, which ideally suited solving the current task. 


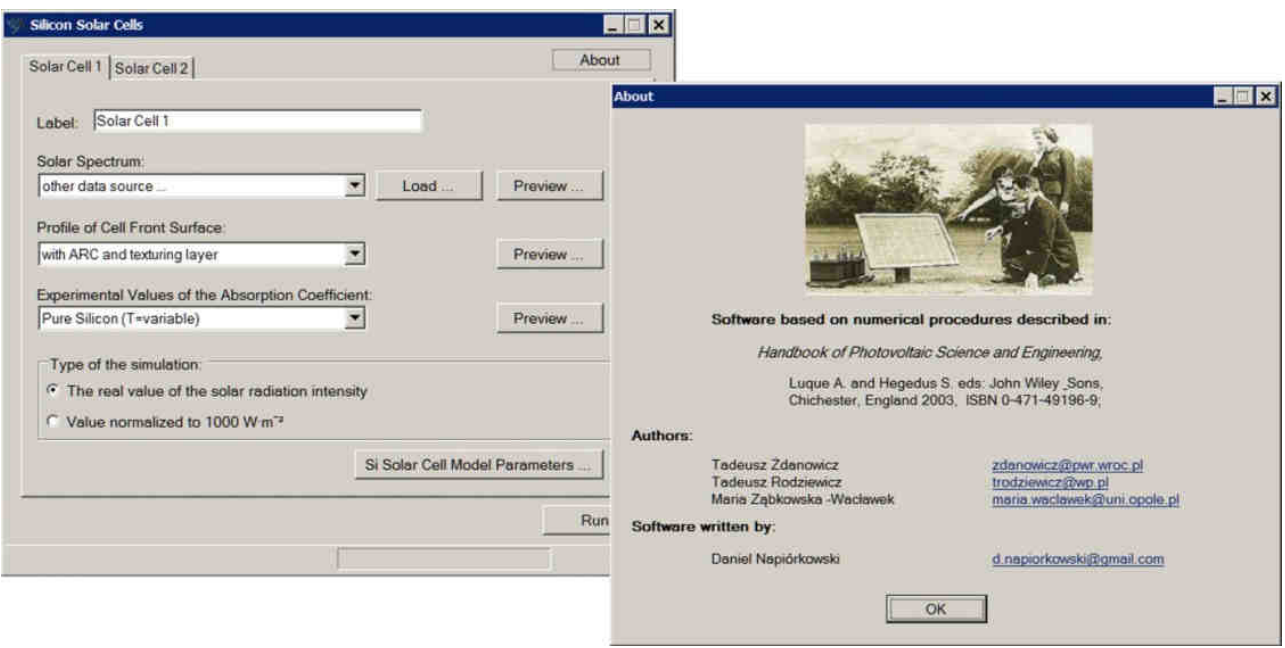

Fig. 3. A tab of input data registry window and setting a cell material and construction parameters - left figure; program information - right figure

Si Solar Cell Model Parameters [25]

Table 1

\begin{tabular}{|c|c|}
\hline Factor/ parameter & Value \\
\hline Temperature of the Cells & $49^{\circ} \mathrm{C}$ \\
\hline Relative Permittivity & 11.7 \\
\hline Break of Material Coefficient & 3.44 \\
\hline Donor Density & $1 \mathrm{e}+020 \mathrm{~cm}^{-3}$ \\
\hline Acceptor Density & $1 \mathrm{e}+015 \mathrm{~cm}^{-3}$ \\
\hline Depth of Building in the Joint & $0.35 \mu \mathrm{m}$ \\
\hline Cell Thickness & $300 \mu \mathrm{m}$ \\
\hline Hole Diffusion Coefficient & $1.5 \mathrm{~cm}^{2} /(\mathrm{Vs})$ \\
\hline Electron Diffusion Coefficient & $35 \mathrm{~cm}^{2} /(\mathrm{Vs})$ \\
\hline Holes Lifetime & $1 \mu \mathrm{s}$ \\
\hline Electron Lifetimes & $350 \mu \mathrm{s}$ \\
\hline $\begin{array}{c}\text { Effective Surface Recombination } \\
\text { Velocities of Holes }\end{array}$ & $100,000 \mathrm{~cm} / \mathrm{s}$ \\
\hline $\begin{array}{c}\text { Effective Surface Recombination } \\
\text { Velocities of Electrons }\end{array}$ & $100 \mathrm{~cm} / \mathrm{s}$ \\
\hline Series Resistance & $0.37 \Omega \mathrm{cm}^{2}$ \\
\hline Shunt Resistance & $100,000 / 276 \Omega \mathrm{cm}^{2}$ \\
\hline
\end{tabular}

Table 2 includes parameters of atmospheric data required to generate the input reference spectrum. Next, the spectrum numerical table was rescaled linearly to five spectrum distributions with total powers: 1000, 700, 500, 300 and $200 \mathrm{~W} / \mathrm{m}^{2}$. Thus obtained files of input spectra with various powers had identical spectral distribution with the same $A P E$ and content of each $U F$ fraction. The data was presented in Figure 4. The spectra were generated in bandwidth $0.28-2.8 \mu \mathrm{m}$ and scaled to obtain the above mentioned power, in order to adjust to actual operating conditions, with the use of a typical pyranometer CM21 made by $\mathrm{K} \& \mathrm{Z}$. When determining energetic parameters, the integration area was restricted 
to $B=0.3-1.7 \mu \mathrm{m}$, in order to adjust to measurement conditions of the actual spectroradiometer used in measurements.

Atmospheric parameter values used in detailed simulation [27]

Table 2

\begin{tabular}{|c|c|}
\hline Air Mass & 1.5 \\
\hline Turbidity $-\beta$ & 0.084 at $500 \mathrm{~nm}(\beta=0.0316)$ \\
\hline Precipitable Water $(\mathrm{w})$ & $1.4164 \mathrm{~atm}-\mathrm{cm}$ \\
\hline Atmosphere Ozone Content $\mathrm{U}_{\mathrm{O} 3}$ & $0.3438 \mathrm{~atm}-\mathrm{cm}$ \\
\hline Reference Atmosphere & Mid Latitude Summer \\
\hline Aerosol Model & S\&F Rural \\
\hline $\mathrm{NO}_{2}$ & $\begin{array}{c}\text { use defaults from selected } \\
\text { atmosphere }\end{array}$ \\
\hline Surface Pressure & $1013.25 \mathrm{mb}$ \\
\hline Latitude & $52^{\circ}$ \\
\hline Altitude & 0 km \\
\hline Extraterrestrial Spectrum & Gueymard 2002 (synetic) \\
\hline Tilted POA & $\begin{array}{c}\text { Global Tilted Irradiance } \\
\text { B = 280-2800 nm }\end{array}$ \\
\hline Spectral Results &
\end{tabular}

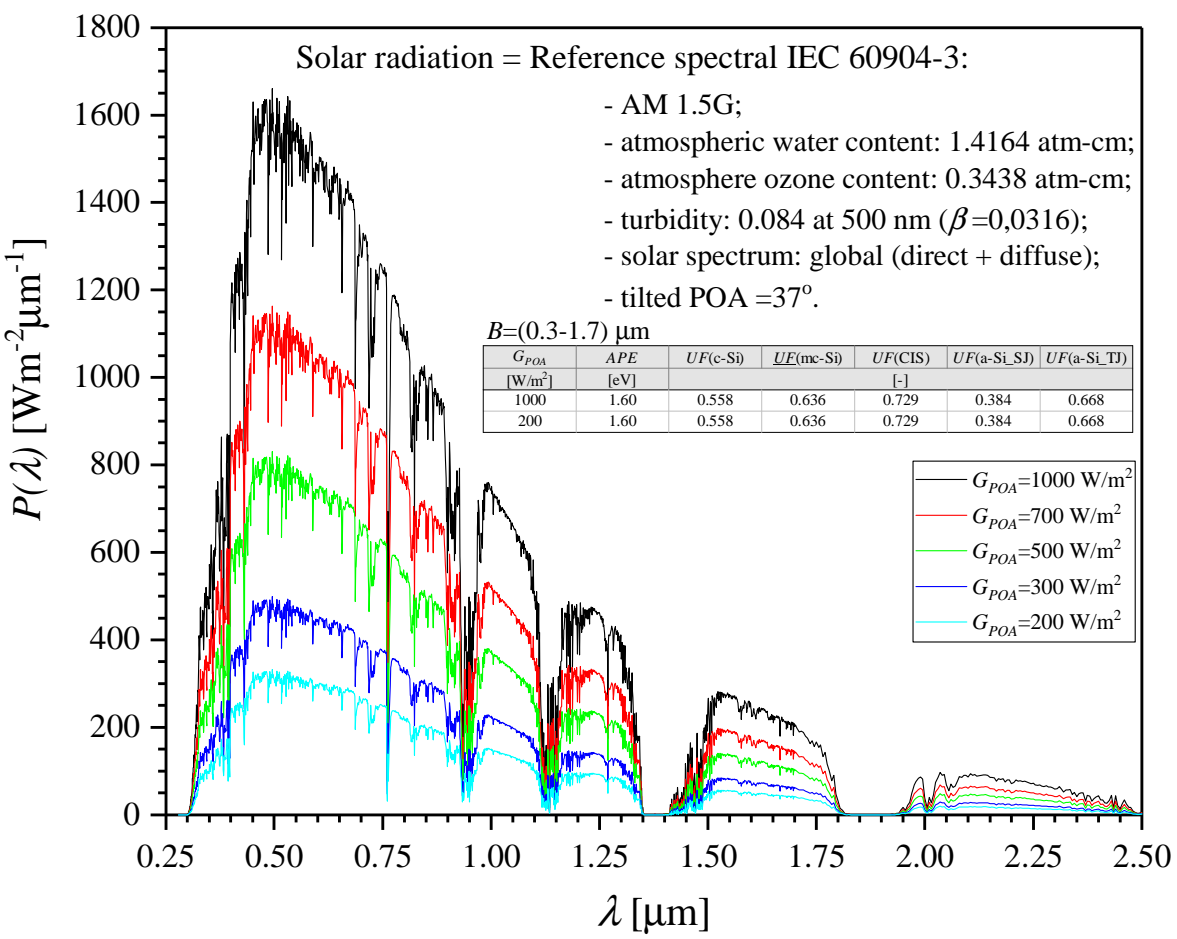

Fig. 4. Distributions of spectra of the radiation lighting the tested PV module used in the analysis, plus their energy characteristics 

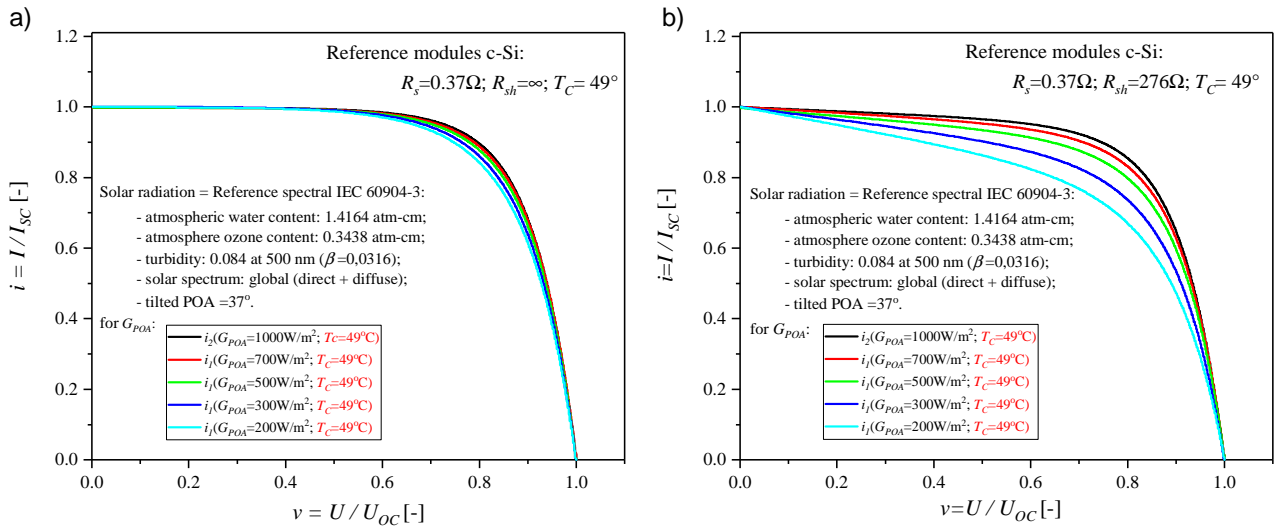

Fig. 5. Graphs of the normalised Blaesser's $I-V$ characteristics: a) for an idealised module, i.e. with no leakage resistance $\left(R_{s h}>100 \mathrm{k} \Omega\right)$, b) for an actual, monocrystalline silicon module with leakage resistance $R_{s h}=276 \Omega$. The temperature of modules in cells was $T_{C}=49^{\circ} \mathrm{C}$

In Figure 5 the value of Blaesser's normalised characteristics are presented, for an idealised module without leakage resistance - Figure 5a, and an actual module with leakage resistance $R_{s h}=276 \Omega$ (Fig. 5b). Both modules had the same cells temperature $T_{C}=49^{\circ} \mathrm{C}$ and serial resistance $R_{s}=0.37 \Omega$. Despite the fact that spectral (energy) parameters of the falling solar radiation spectrum were identical, with the only difference of lighting intensity, in both cases the normalised characteristics differ considerably.

In the case of an idealised module without leakage resistance $R_{s h}=\infty$ (Fig. 5a), the curves almost cover each other in the full range of lighting value changes. They differ only at the bend, so called "elbow", which is the effect of a non-linear component occurrence in $\left(G_{2} / G_{1}\right)$ in (10). In the area of low values of the reduced voltages " $v$ " i.e. for $v<0.6$, the curves have the same, zero inclination. In the area of reduced voltages $v \rightarrow 1$, i.e. close to $v \cong 1$, all curves go down with the same inclination equal to $1 / R_{s}$.
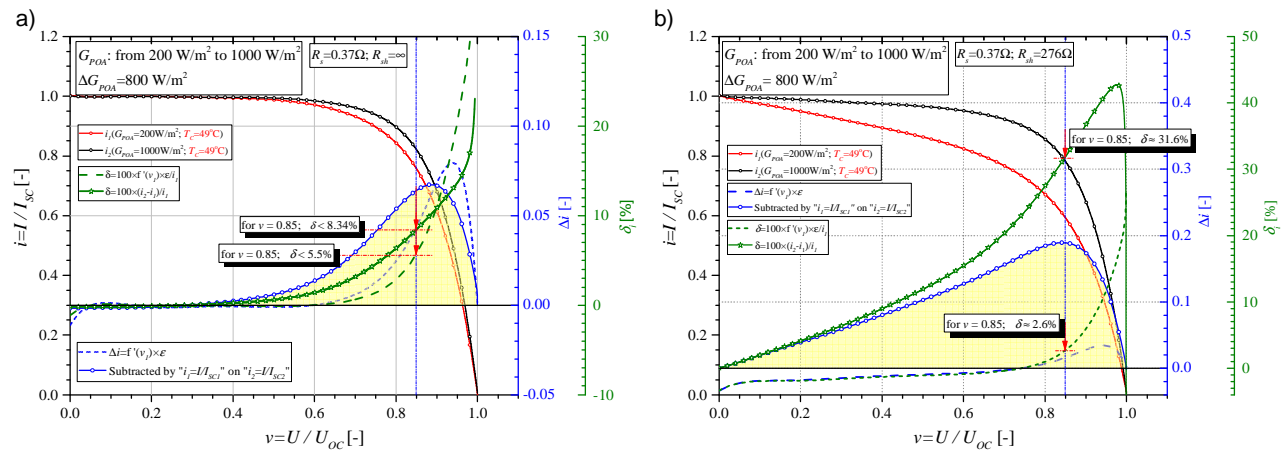

Fig. 6. The influence of the module leakage resistance $\left(R_{s h}\right)$ on the speed of decreasing of the normalised $I-V$ characteristics and the translation error $\delta_{i}$ for the translation in the range from 200 to $1000 \mathrm{~W} / \mathrm{m}^{2}$ 
In the case of an actual module, with leakage resistance $R_{s h}=276 \Omega$ (Fig. 5b), the curves are at a considerable distance. The largest distance occurs during the largest load of the module, i.e. in the area of low values of reduced voltages " $v$ " and low values of falling radiation, i.e. for low values of photocurrents generated in the modules. In the area of reduced voltages $v \rightarrow 1$, i.e. close to $v \cong 1$, as in figure a), all curves go down with the same inclination equal to $1 / R_{s}$. The occurring differences, caused by the influence of leakage resistance $R_{s h}$, in the module, become even more visible in the measured characteristics, along with decreasing their lighting values $G_{P O A}$ below $500 \mathrm{~W} / \mathrm{m}^{2}$.

a)

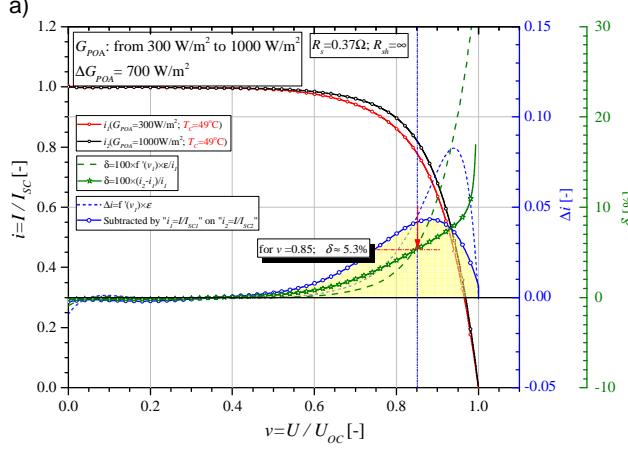

b)

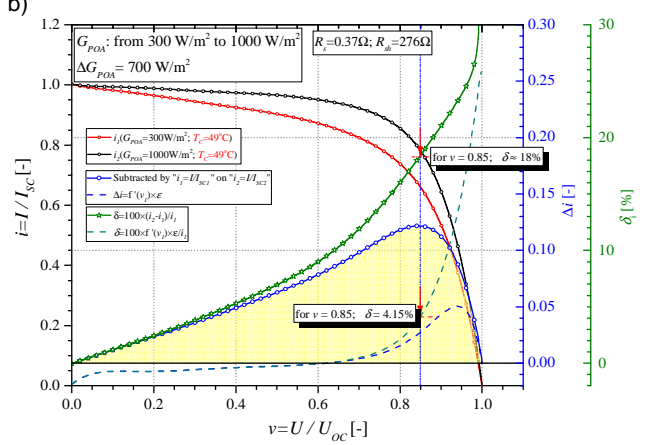

Fig. 7. The influence of the module leakage resistance $\left(R_{s h}\right)$ on the speed of decreasing of the normalised $I-V$ characteristics and the translation error $\delta_{i}$ for the translation in the range from 300 to $1000 \mathrm{~W} / \mathrm{m}^{2}$

a)

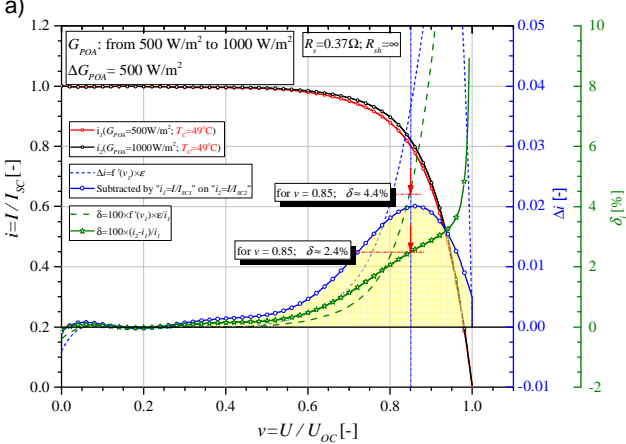

b)

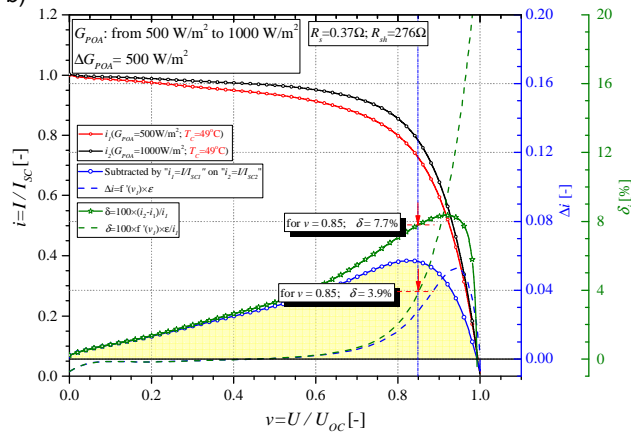

Fig. 8. The influence of the module leakage resistance $\left(R_{s h}\right)$ on the speed of decreasing of the normalised $I-V$ characteristics and the translation error $\delta_{i}$ for the translation in the range from 500 to $1000 \mathrm{~W} / \mathrm{m}^{2}$

The following graphs from Figures 6 to 9 present the results of characteristics translations and the flow of the function of errors for the above mentioned operations, obtained for the normalised characteristics from Figures $5 \mathrm{a}$ and $\mathrm{b}$. The $I-V$ curves from Figure 5a refer to an idealised module without leakage resistance (i.e. $R_{s h}=\infty$ ), the curves from Figure $5 \mathrm{~b}$ for an actual module with $R_{s h}=276 \Omega$. The $I-V$ curve in red and black marked $i_{1}\left(G_{P O A}=200 \mathrm{~W} / \mathrm{m}^{2} ; T_{C}=49^{\circ} \mathrm{C}\right)$ and $i_{2}\left(G_{P O A}=1000 \mathrm{~W} / \mathrm{m}^{2} ; T_{C}=49^{\circ} \mathrm{C}\right)$ illustrate 
the reduced $I-V$ characteristics of the modules, obtained in operation condition defined in the graphs. The dashed blue curve - marked $\Delta i=\mathrm{f}^{\prime}\left(v_{1}\right) \times \mathcal{E}$ - illustrates the flow of absolute error for translation of $i_{1}$ curve, from the conditions $\left(G_{P O A}=200 \mathrm{~W} / \mathrm{m}^{2} ; T_{C}=49^{\circ} \mathrm{C}\right)$ to $\left(G_{P O A}=1000 \mathrm{~W} / \mathrm{m}^{2} ; T_{C}=49^{\circ} \mathrm{C}\right)$, determined according to (26). The blue curve with a circle, marked as: Subtracted by " $i_{1}=I / I_{S C 1}$ " on " $i_{2}=I / I_{S C 2}$ " - the actual, total translation error of the reduced Blaesser's characteristics, occurring during translation from $G_{P O A 1}$ to $G_{P O A 2}$, at the same cells temperature in the module $\left(T_{C}\right.$ - const), determined according to (38). The dashed green curve - marked in the graph as $\delta=100 \times \mathrm{f}^{\prime}\left(v_{1}\right) \times \varepsilon / i_{1}$ - the absolute error flow for the same translation, determined according to (27). Whereas the green curve with an asterisk - marked in the graphs as $\delta=100 \times\left(i_{2}-i_{1}\right) / i_{1}$ - the absolute error flow of translation, determined according to (39). The graphs on the left in Figures 6-9, marked a present the obtained translation data for an idealised module (i.e. for $R_{s h}=\infty$ ), those on the right - for an actual module with typical resistance as in the modules with c-Si $R_{s}=276 \Omega$.

a)

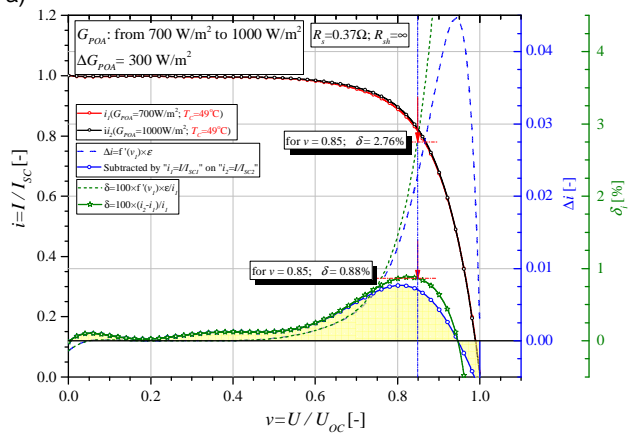

b)

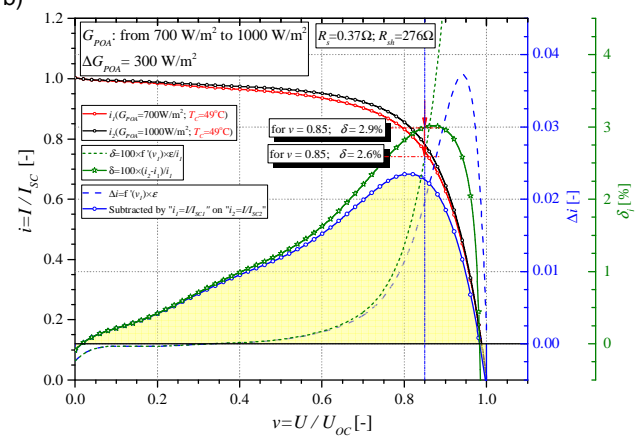

Fig. 9. The influence of the module leakage resistance $\left(R_{s h}\right)$ on the speed of decreasing of the normalised $I-V$ characteristics and the translation error $\delta_{1}$ for the translation in the range from 700 to $1000 \mathrm{~W} / \mathrm{m}^{2}$

Values of absolute errors of $I$ - $V$ curves translation, depending on the range and calculation method

\begin{tabular}{|c|c|c|c|c|}
\hline$G_{P O A}$ & \multicolumn{2}{|c|}{$R_{s}=0.37 \Omega ; R_{s h}=\infty$} & \multicolumn{2}{|c|}{$R_{s}=0.37 \Omega ; R_{s h}=276 \Omega$} \\
\hline$\left[\mathbf{W} / \mathbf{m}^{2}\right]$ & $\begin{array}{l}\delta=100 \times f^{\prime}(v) \times \varepsilon / i_{1} \\
\text { according to }(27)\end{array}$ & $\begin{array}{c}\delta=100 \times\left(i_{1}-i_{2} / i_{1}\right) \\
\text { according to }(39)\end{array}$ & $\begin{array}{l}\delta=100 \times f^{\prime}(v) \times \varepsilon / i_{1} \\
\text { according to }(27)\end{array}$ & $\begin{array}{c}\delta=100 \times\left(i_{1}-i_{2} / i_{1}\right) \\
\text { according to }(39)\end{array}$ \\
\hline & {$[\%]$} & {$[\%]$} & {$[\%]$} & {$[\%]$} \\
\hline 200 & 5.5 & 8.3 & 2.6 & 31.6 \\
\hline 300 & 5.3 & 5.3 & 4.1 & 18.0 \\
\hline 500 & 4.4 & 2.4 & 3.9 & 7.7 \\
\hline 700 & 2.8 & 0.9 & 2.9 & 2.6 \\
\hline
\end{tabular}

An analysis of the obtained results included in Figures 6-9 and Table 3 leads to the following conclusions:

1. All results regarding translation errors of the normalised $I-V$ characteristics to STC conditions, irrespective of the accepted method, within the values $G_{P O A}>500 \mathrm{~W} / \mathrm{m}^{2}$ have the values lower than $8 \%$, which is comparable with the results of validation of cells calibration procedures for the methods from 1 to 3 , according to [3]. 
2. In the range of values $G_{P O A} \geq 700 \mathrm{~W} / \mathrm{m}^{2}$, for the actual modules having leakage resistance $R_{s h}=276 \Omega$, there is equalisation of translation error, calculated according to Blaesser's method, i.e. (26) and (27), with the actual results determined according to (38) and (39).

3. The significance of translation error and its flow in the function " $v$ ", calculated according to (26) and (27) and the level of distortion versus the actual value, determined according to (38) and (39) strictly depends on the shape of I-V characteristics, therefore on the value present in the resistance module $R_{\text {sh }}$. For the modules with low leakage (i.e. large values of $R_{s h}$, Figs. 6-9a) - the obtained values are similar within the range of low voltages, i.e. up to so-called elbow of $I-V$ characteristics, occurring for $v<(0.7-0.8)$. Additionally, during translation to STC from the range $G_{P O A} \geq 500 \mathrm{~W} / \mathrm{m}^{2}$ - the value of the calculated translation error of normalised I-V curves according to the formula (27) and the measured actual, according to (39) is within the range of 1\%, which fully conforms with [6]. However, in the case of higher leakage in a module (i.e. for low values $R_{s h}$, Figs. 6-9b) - the rule for the low voltages " $v$ " range does not apply.

4. If during translation of normalised $I-V$ curves of modules from the area of low $G_{P O A}$ values to STC conditions - the occurrence of actual leakage resistance $R_{s h}$ is not taken into consideration, it results in a major distortion of the flow calculated according to Blaesser's method (26) and (27), i.e. a translation error, in lower ranges of normalised voltages ("v"), in particular. The situation is much improved in the case of testing idealised modules, i.e. with no leakage resistance $\left(R_{s h}=\infty\right)$, however, this does not reflect the real conditions.

\section{Simplified method for determining actual translation errors:}

Using the definition of the Blaesser's reduced characteristics (8), where the expressions $i_{1}=f\left(v_{1}\right)$ and $i_{2}=f\left(v_{2}\right)$ present the reduced $I-V$ characteristics for the conditions, respectively: $\left(G_{1}, T_{C 1}\right)$ and $\left(G_{2}, T_{C 2}\right)$, then using to (26) and (27), the absolute and relative translation error of the I-V curve of the module, from the conditions $\left(G_{1}, T_{C 1}\right)$ to $\left(G_{2}, T_{C 2}\right)$ can be presented in the form, respectively:

$$
\begin{gathered}
\Delta i=\underbrace{f\left(v_{1}+\varepsilon\right)}_{i_{2}}-\underbrace{f\left(v_{1}\right)}_{i_{1}}=f\left(v_{2}\right)-f\left(v_{1}\right) \\
\delta_{i}[\%]=100 \frac{i_{2}-i_{1}}{i_{1}}=100 \frac{f\left(v_{2}\right)-f\left(v_{1}\right)}{f\left(v_{1}\right)}
\end{gathered}
$$

The expression (37) in the form of a difference $f\left(v_{2}\right)-f\left(v_{1}\right)$, means the numerical result of the difference of two processes, for example with the use of typical software for measurement data processing (e.g. OriginPro). The result of the subtraction was presented in Figures 6-10, marked as: Subtracted by " $i_{1}=I / I_{S C 1}$ " on " $i_{2}=I / I_{S C 2}$ ".

Whereas the expression (39) means that it is necessary to divide the difference of two processes by the stabilised first one. It should be remembered that numerical operations in these processes can be carried out only in the conditions of unification of the " $v$ " voltage variable, for both processes. 
The above presented Blaesser's method of determining translation errors according to (38) and (39) is a very simple operation in order to obtain reliable results, without the need to carry out very complex mathematical operations!!

The obtained results are comparable to earlier presented methods, but there are no limitations. In Figure 10 the obtained results of translation error of the normalised $I-V$ curves of an actual polycrystalline mc-Si module are presented, for the translation from the measurement conditions $\left(G=467 \mathrm{~W} / \mathrm{m}^{2}\right.$ and $\left.T_{C}=47^{\circ} \mathrm{C}\right)$ to the conditions $\left(G=978 \mathrm{~W} / \mathrm{m}^{2}\right.$ and $\left.T_{C}=62^{\circ} \mathrm{C}\right)$ and $\left(G=817 \mathrm{~W} / \mathrm{m}^{2}\right.$ and $\left.T_{C}=62^{\circ} \mathrm{C}\right)$, i.e. from the area of measurement conditions of $I-V$ characteristics more than $450 \mathrm{~W} / \mathrm{m}^{2}$. The graphs were plotted using the expressions (26) and (27) and the simplified method, i.e. the expressions (38) and (39). It should be noted that many obtained results are similar; it should be remembered that a guaranteed quality of translation of the Blaesser's normalised curves to STC conditions can be maintained only measurements for $\left.G_{P O A}>600 \mathrm{~W} / \mathrm{m}^{2}[6]\right)$. The only difference is the lack of differentiation by the translation error in voltage axis $(\varepsilon)$ - the error originating from the increase of cells temperature $T_{C}$ in the module from the error from the increase of lighting level $G$ (see Fig. 10). These factors have contradictory influence on the increases of output voltages in modules.

a)

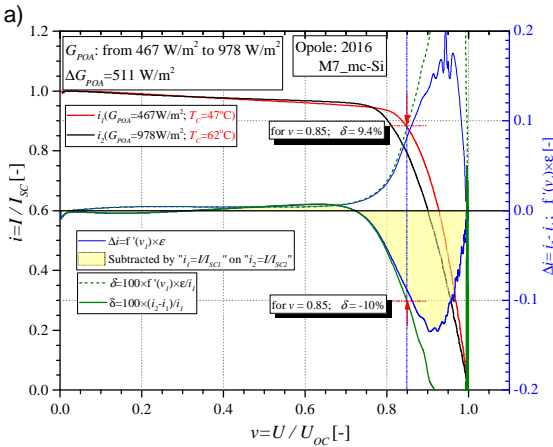

b)

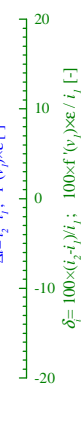

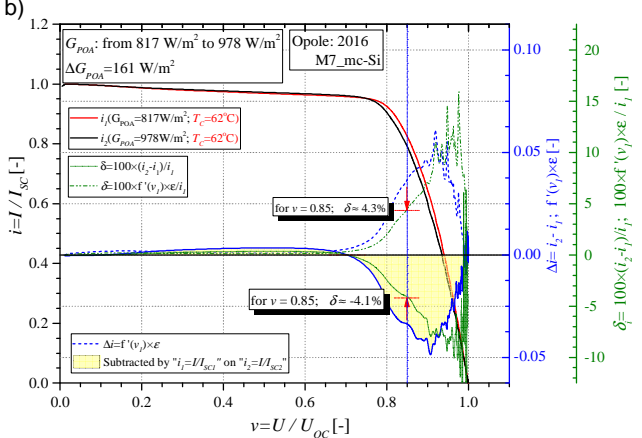

Fig. 10. Graph of absolute and relative errors of a $I-V$ curve translation to the conditions $\left(G=978 \mathrm{~W} / \mathrm{m}^{2}\right.$ and $T_{C}=62^{\circ} \mathrm{C}$ ) from the area $G>450 \mathrm{~W} / \mathrm{m}^{2}$ for an actual, polycrystalline PV module, carried out for translation for the value: a) $511 \mathrm{~W} / \mathrm{m}^{2}$ and b) $161 \mathrm{~W} / \mathrm{m}^{2}$. The graphs were plotted using the expressions (26) and (27) and the simplified method, i.e. the expressions (38) and (39)

In further analyses, the presented new method based on (38) and (39) shall be the main method in practical application for determining translation errors, as he most reliable and not limited by any restrictions.

\section{Research results}

The assessment of the technical condition of the working PV modules and the level of degradation of their construction was carried out using the characteristics of the $I-V$ of tested modules that were recorded for two extremely different days occurring in areas with higher latitudes. The first one, characterized by low insolation and average temperatures, which is referred to in IEC 61853-4 ED1 (IEC 61853, DRAFT 82/254) [28] as the so-called 'typical warm and very cloudy day LIMT' (Low Irradiance, Medium Temperature), and the 
second one - hot summer day with high insolation - called HIHT (High Irradiance, High Temperature).

a)

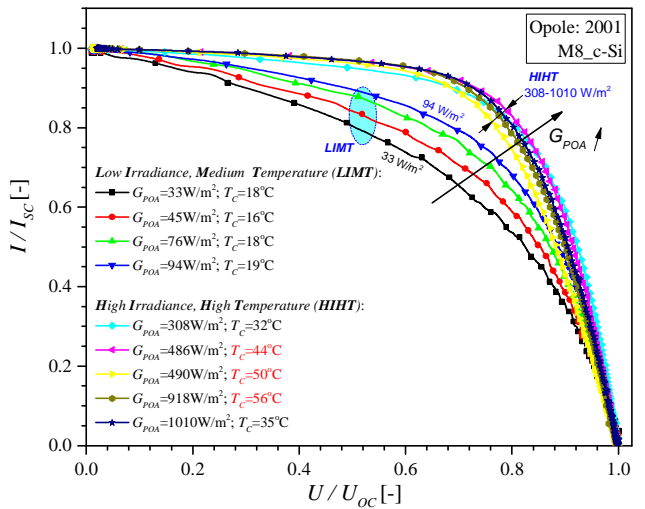

b)

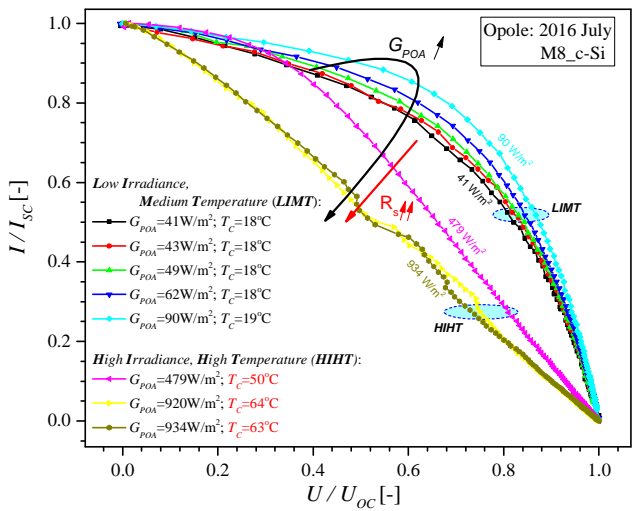

Fig. 11. Graphs of the normalised Blaesser's $I-V$ characteristics for a monocrystalline module (c-Si): a) at the beginning of exploitation, i.e. from 2001, and b) after 16 years of use, i.e. from 2016

a)

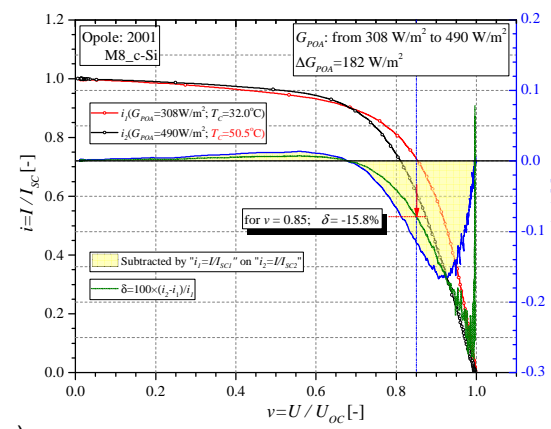

c)

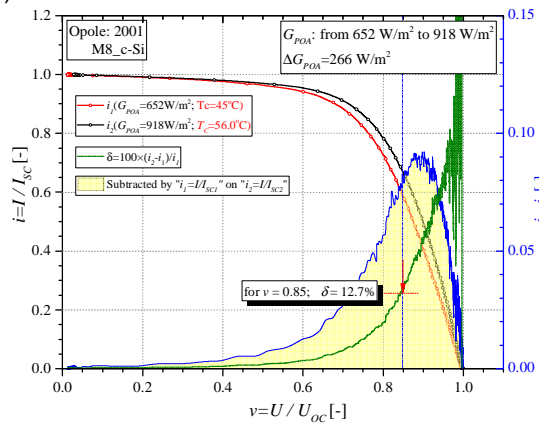

b)
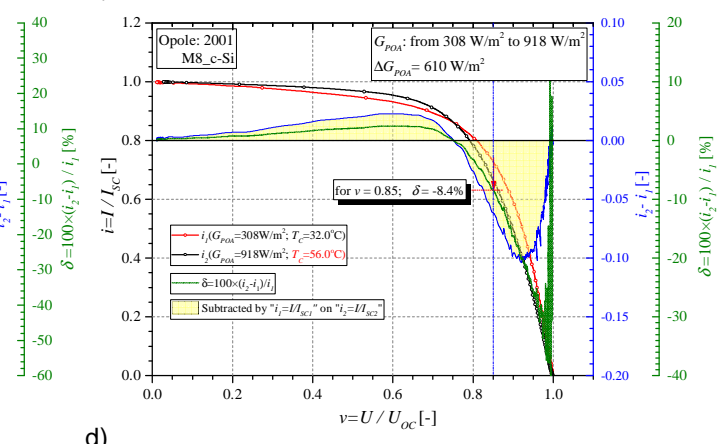

d)

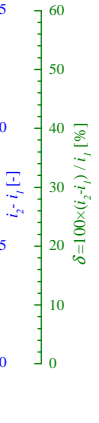

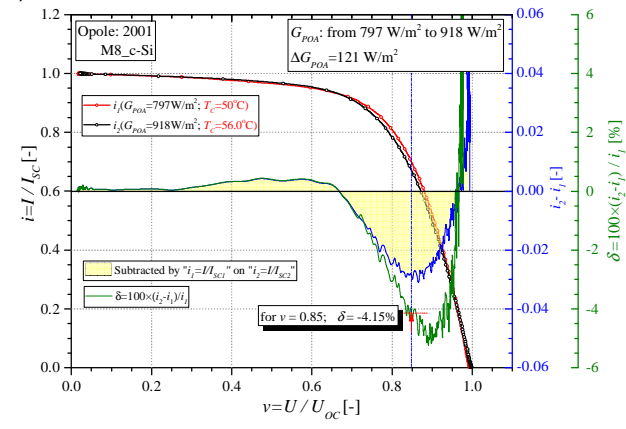

Fig. 12. Graphs of absolute and relative $I-V$ translation errors for an actual, monocrystalline (c-Si) PV module, for the translation value: a) $182 \mathrm{~W} / \mathrm{m}^{2}$; b) $266 \mathrm{~W} / \mathrm{m}^{2}$; c) $610 \mathrm{~W} / \mathrm{m}^{2}$ and d) $121 \mathrm{~W} / \mathrm{m}^{2}$ 
Figure 11 presents graphs of the normalised Blaesser's I-V characteristics for a monocrystalline module (c-Si): a) at the beginning of exploitation, i.e. from 2001, and b) after 16 years of use in extreme operation conditions, i.e. from 2016. The distributions obtained in Figure 11a and the flow of translation of $I-V$ curves function from the initial exploitation period (i.e. from 2001 - Fig. 12), confirm good quality of the construction of the monocrystalline module used in the tests. However, 16 years of exploitation in extreme conditions caused considerable degradation of materials and construction of the tested PV module, noticed in the changes of distribution of the module normalised $I-V$ curves (see Fig. 11b). The presence of a very large increase of serial resistance $R_{s}$ can be noticed, already after exceeding the solar radiation value above $G_{P O A}>(150-300) \mathrm{W} / \mathrm{m}^{2}$ and in the range of higher temperatures of cells operation $T_{C}$ in the PV module. This is caused by construction and material degradation, including, for example, cracks in a module cell or cells, structural damage of a cell surface layer, including various hairline cracks, etc.

a)

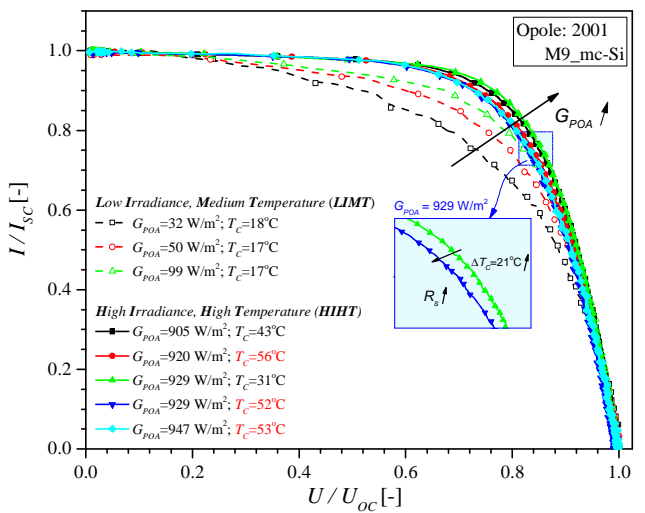

b)

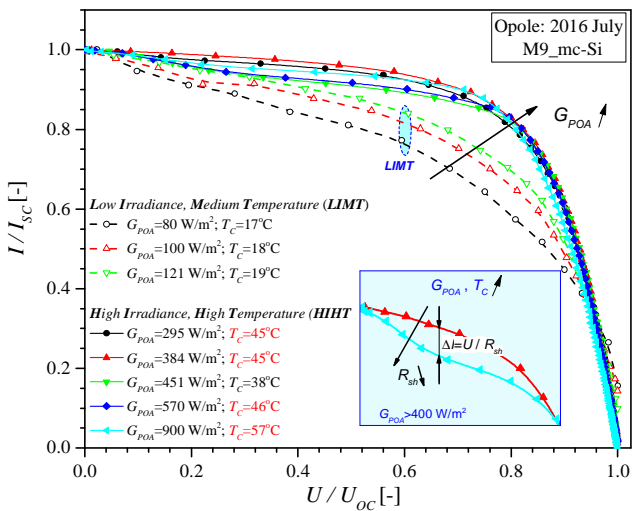

Fig. 13. Graphs of the normalised Blaesser's $I$ - $V$ characteristics for a polycrystalline module (mc-Si): a) at the beginning of exploitation, i.e. from 2001, and b) after 16 years of use, i.e. from 2016

Figure 13 presents graphs of the normalised Blaesser's I-V characteristics for a polycrystalline module (mc-Si): a) at the beginning of exploitation, i.e. from 2001, and b) after 16 years of use. The distributions obtained in Figure 13a and the flow of translation of $I-V$ curves function from the initial exploitation period (i.e. from 2001 - Figure $14 \mathrm{a}, I-V$ red curve), versus the $I-V$ black curve from 2016, confirm good quality of the polycrystalline module absorber.

The effects of a PV module 16 years of use: increase of the mc-Si module leakage (i.e. decrease of $R_{s h}$ resistance), and the occurrence of a strong correlation between the increase of lighting intensity level $G_{P O A}$, cells operation temperature $T_{C}$ and a decreasing $R_{S h}$ (increase of the module leakage - Fig. 13b). Moreover, in Figures $13 \mathrm{~b}$ and 14b,c one can notice the appearance of a characteristic discontinuity in the characteristics of low " $i$ " current values, so-called discontinuity in the vicinity of a module $U_{O C}$ voltage with low lighting conditions, occurring during periods of high level of insolation and temperatures. The phenomenon described in [1] frequently occurring in amorphous modules, is an effect of the slow degradation of a cell crystalline structure. 
a)

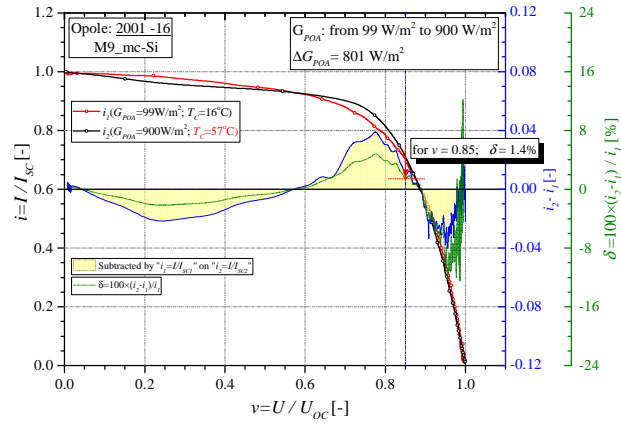

c)

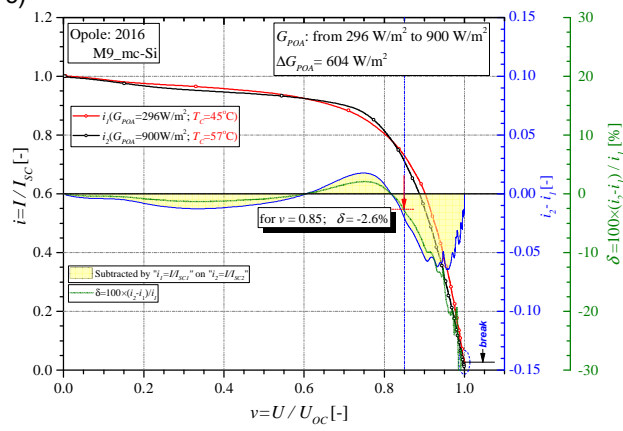

b)

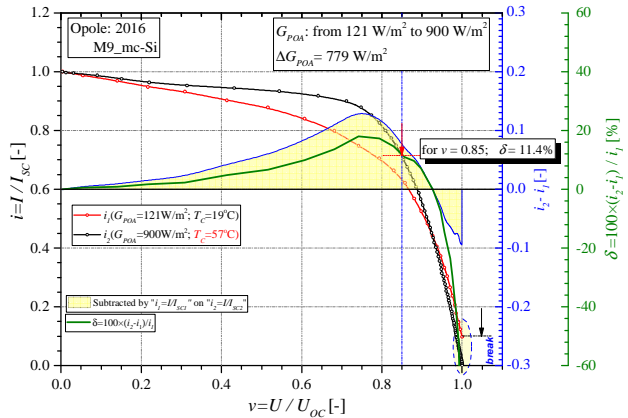

d)

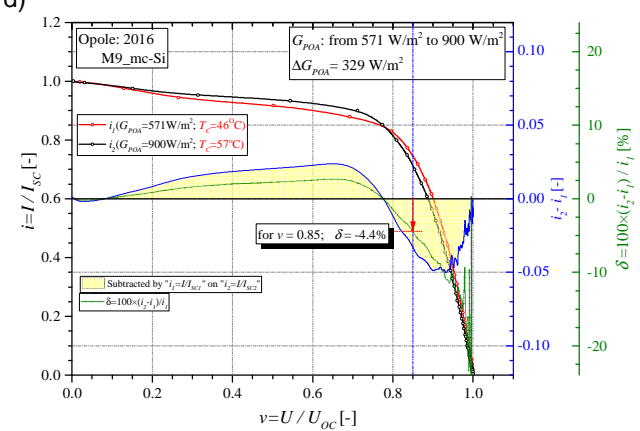

Fig. 14. Graphs of absolute and relative $I-V$ translation errors for an actual, polycrystalline (mc-Si) PV module, for the translation value: a) $801 \mathrm{~W} / \mathrm{m}^{2}$; b) $779 \mathrm{~W} / \mathrm{m}^{2}$; c) $604 \mathrm{~W} / \mathrm{m}^{2}$ and d) $329 \mathrm{~W} / \mathrm{m}^{2}$

a)

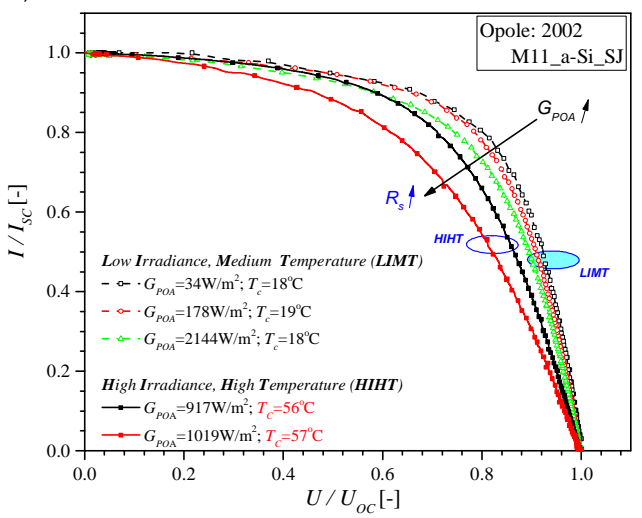

b)

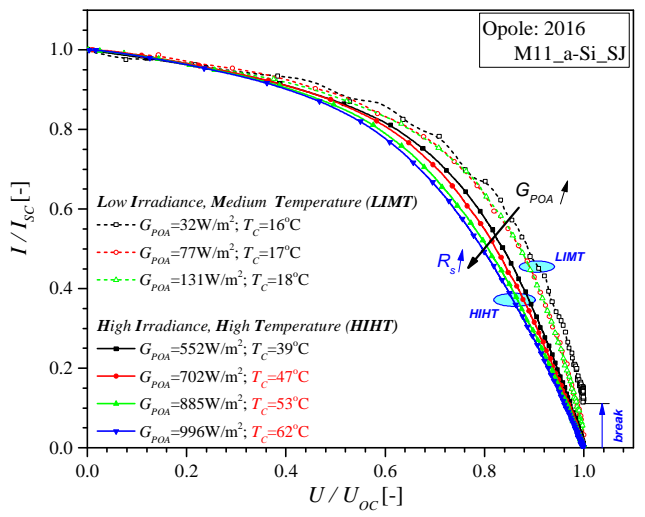

Fig. 15. Graphs of the normalised Blaesser's $I-V$ characteristics for a single-joint module of amorphous silicon (a-Si_SJ): a) at the beginning of exploitation (after initial ageing period), i.e. from 2002, and b) after 15 years of use, i.e. from 2016

In a single-joint PV module of amorphous silicon, due to high $R_{s}$ resistance and low $R_{s h}$, the translation error of $I-V$ curves to STC conditions, even during an initial period of 
exploitation, i.e. after the initial ageing period, was very high, amounting to: $\delta=36 \%$ for the change $G_{P O A}=178 \rightarrow 1019 \mathrm{~W} / \mathrm{m}^{2}, \delta=31 \%$, for $G_{P O A}=214 \rightarrow 1019 \mathrm{~W} / \mathrm{m}^{2}, \delta=28 \%$, for $G_{P O A}=599 \rightarrow 1019 \mathrm{~W} / \mathrm{m}^{2}, \delta=20 \%$, for $G_{P O A}=917 \rightarrow 1019 \mathrm{~W} / \mathrm{m}^{2}$. It presented high dependence of the increase of $R_{s}$ on the increase of $G_{P O A}$ and temperature $T_{C}$, with simultaneously increasing $R_{s h}$.

a)

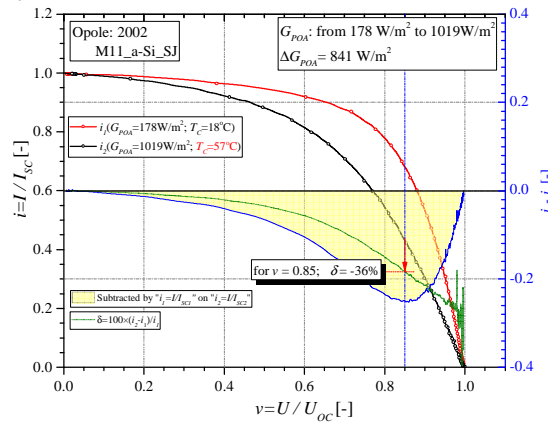

c)

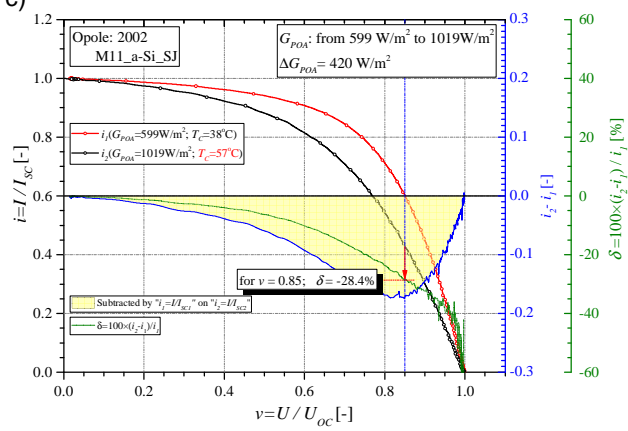

b)

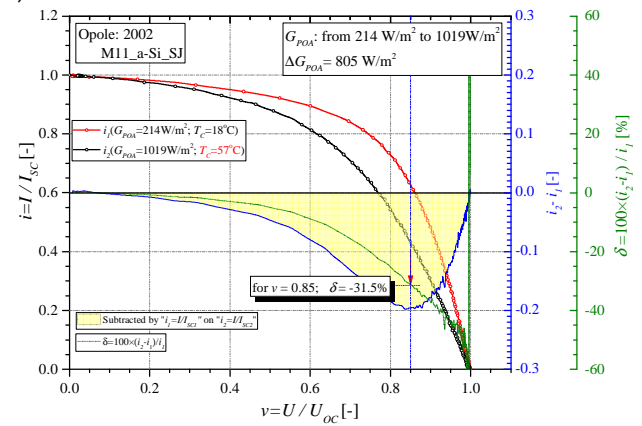

d)

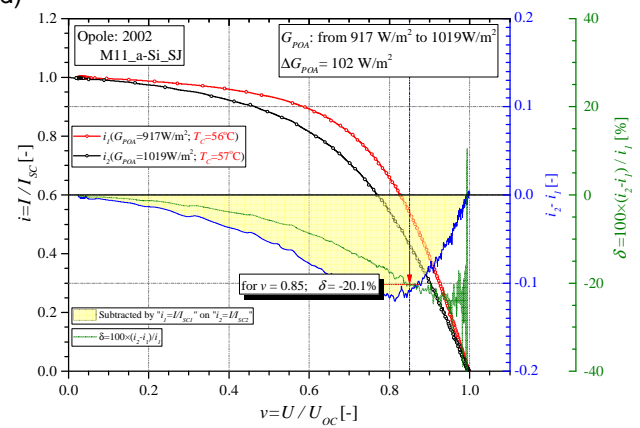

Fig. 16. Graphs of absolute and relative $I-V$ translation errors for an actual, single-joint PV module of amorphous silicon (a-Si_SJ), for the translation value: a) $841 \mathrm{~W} / \mathrm{m}^{2}$; b) $805 \mathrm{~W} / \mathrm{m}^{2}$; c) $420 \mathrm{~W} / \mathrm{m}^{2}$ and d) $102 \mathrm{~W} / \mathrm{m}^{2}$

The effects of a 16-year exploitation of a PV module: decrease of a module FF coefficient, increase of $R_{s}$, and decrease of $R_{s h}$ resistance. Moreover, a characteristic discontinuity appeared in the characteristics of low " $i$ " current values, so-called discontinuity in the vicinity of a module $U_{O C}$ voltage with low lighting conditions (Fig. 15b), occurring during periods of high level of insolation and temperatures; the phenomenon has been described in [1].

In the case of a triple-joint module made of amorphous silicon (Figs. 17 and 18), no degradation traces were identified during 14 years of exploitation in the same extreme conditions. Similarly to the module a-Si_TJ, the CIS module (see Figs. 19 and 20) had no visible traces of degradation after 14 years of exploitation, except for a slight increase of $R_{S}$ resistance and the appearance of the influence of radiation increase $G_{P O A}$ and cells temperature on the increase of $R_{s}$. 
a)

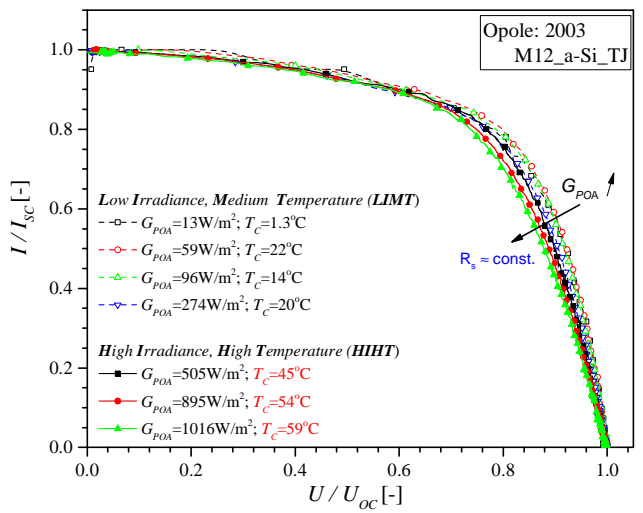

b)

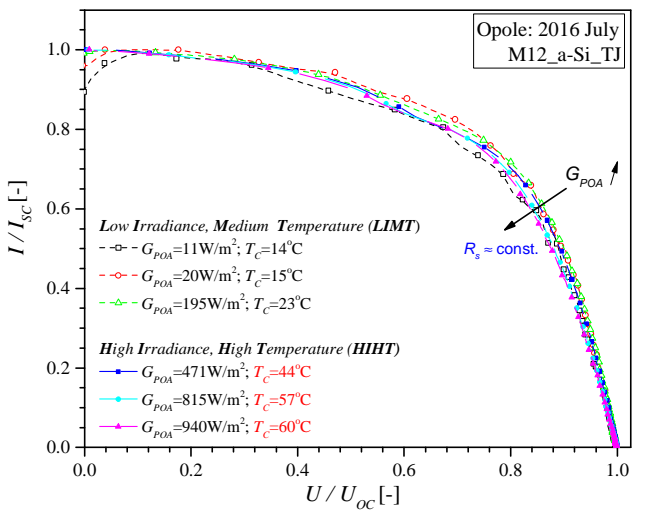

Fig. 17. Graphs of the normalised Blaesser's $I-V$ characteristics for a triple-joint module of amorphous silicon (a-Si_TJ): a) at the beginning of exploitation (after initial ageing period), i.e. from 2002, and $b$ ) after 14 years of use, i.e. from 2016

a)

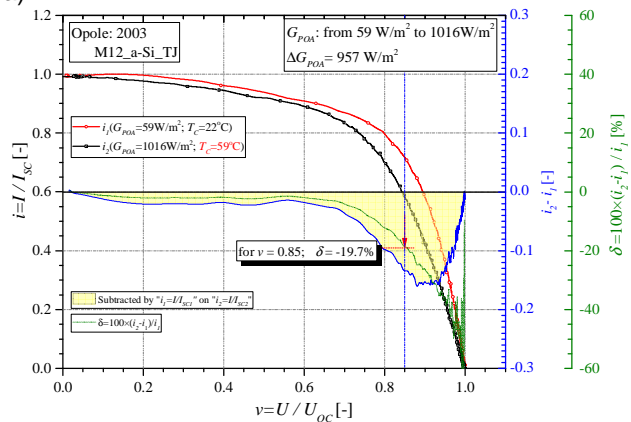

c)

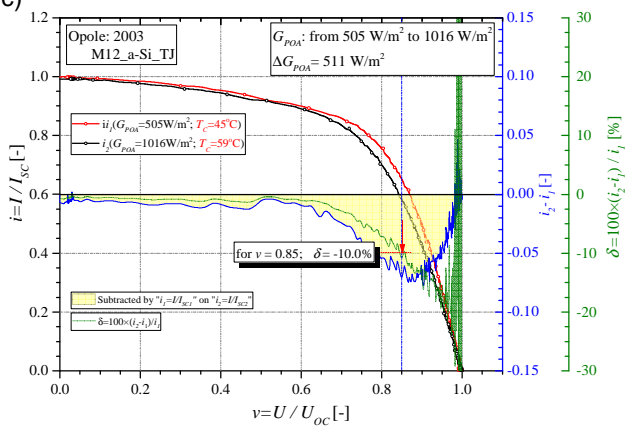

b)

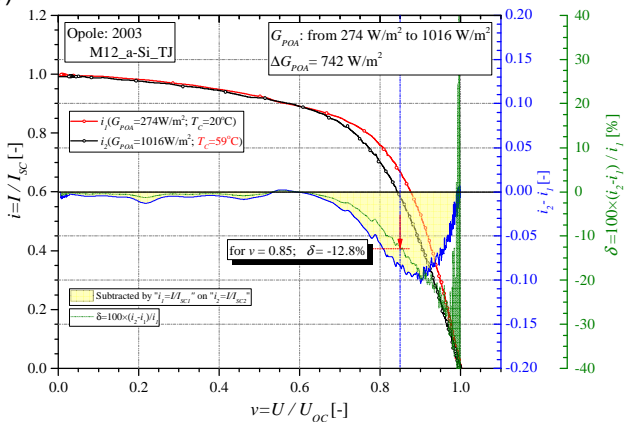

d)

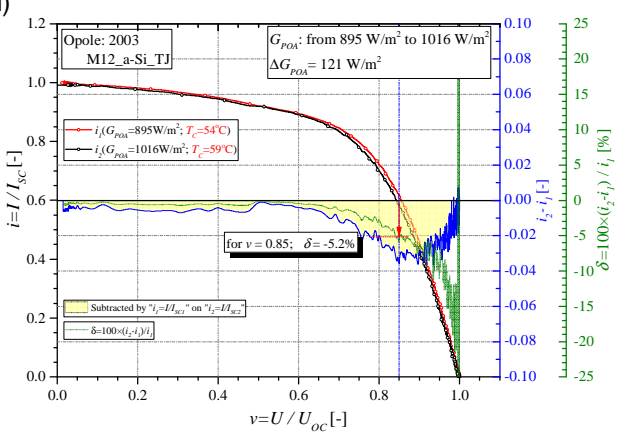

Fig. 18. Graphs of absolute and relative $I-V$ translation errors for an actual, triple-joint PV module of amorphous silicon (a-Si_TJ), for the translation value: a) $957 \mathrm{~W} / \mathrm{m}^{2}$; b) $742 \mathrm{~W} / \mathrm{m}^{2}$; c) $511 \mathrm{~W} / \mathrm{m}^{2}$ and d) $121 \mathrm{~W} / \mathrm{m}^{2}$ 
a)

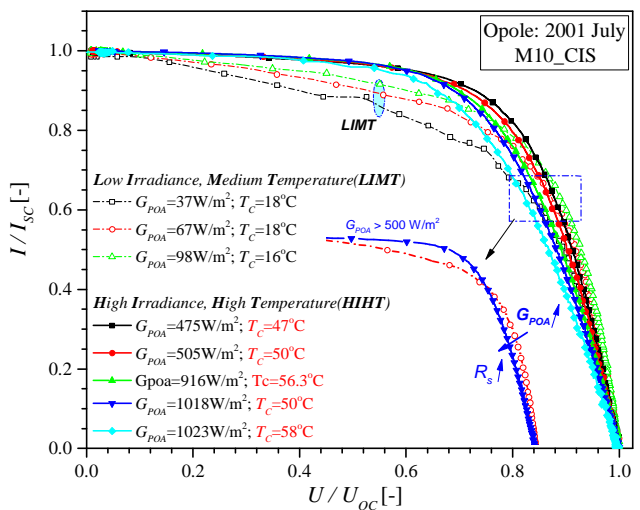

b)

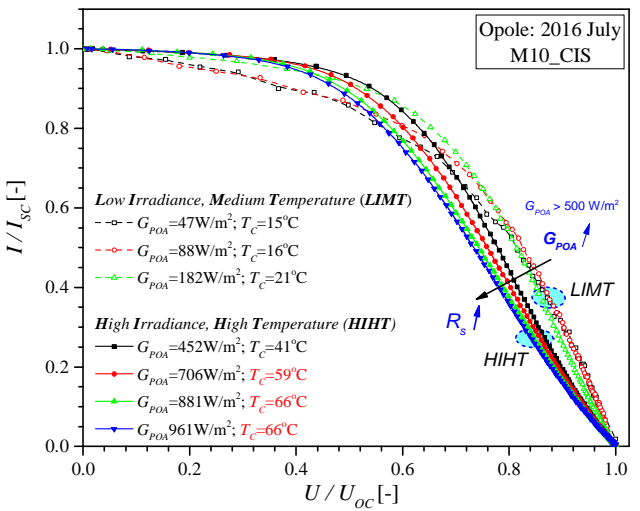

Fig. 19. Graphs of the normalised Blaesser's $I$ - $V$ characteristics for a CIS module: a) at the beginning of exploitation, i.e. from 2001, and b) after 16 years of use, i.e. from 2016

a)

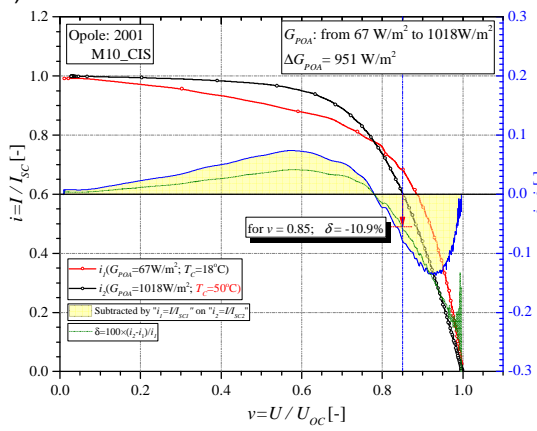

c)

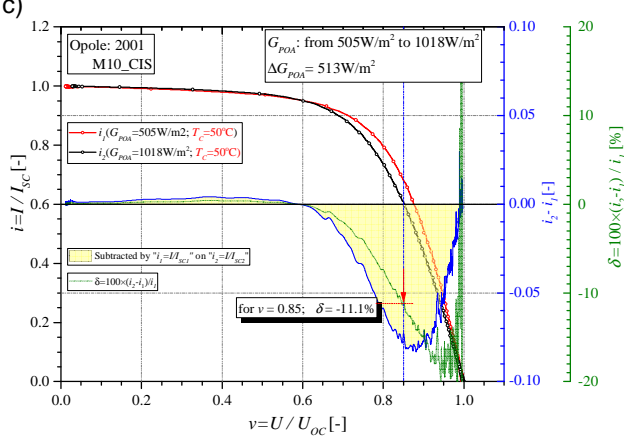

b)

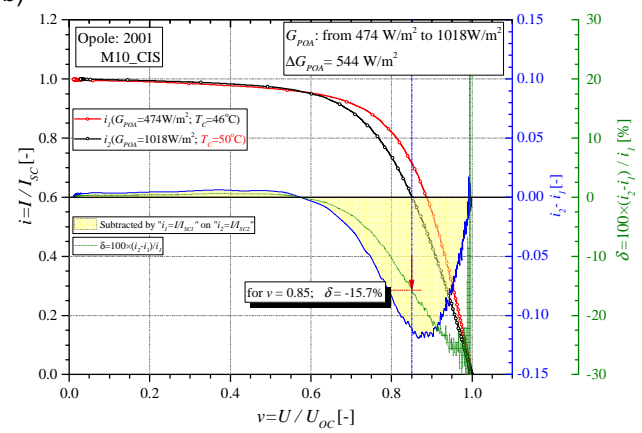

d)

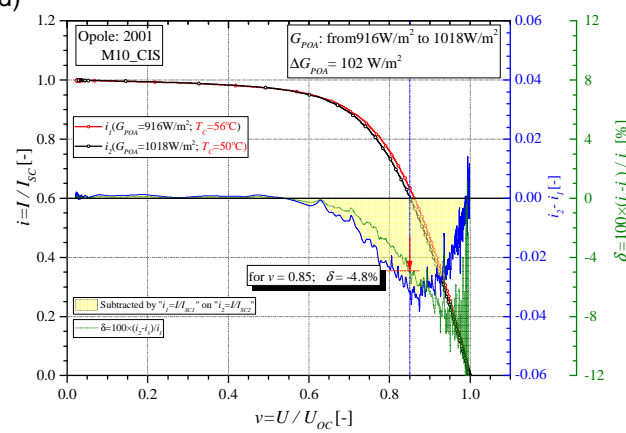

Fig. 20. Graphs of absolute and relative $I-V$ translation errors for an actual, CIS PV module, for the translation value: a) $950 \mathrm{~W} / \mathrm{m}^{2}$; b) $544 \mathrm{~W} / \mathrm{m}^{2}$; c) $513 \mathrm{~W} / \mathrm{m}^{2}$ and d) $102 \mathrm{~W} / \mathrm{m}^{2}$

\section{Conclusions}

The following conclusions and observations can be drawn from the analysis of the above mentioned analysis method: 
1. The presented method of using the reduced $I-V$ characteristics, according to Blaesser's method, in which after normalisation of $I / I_{S C}$ and $U / U_{O C}$ values, the characteristics are automatically rescaled to the range from 0 to 1 - in each axis, offers the opportunity to place all characteristics in a single graph, irrespective of atmospheric conditions during measurements taking.

2. Placing all characteristics in a single graph, irrespective of atmospheric conditions during measurements taking, provides perfect opportunities of making analyses of the influence of such factors as $G_{P O A}$ or $T_{C}$ of a module cells on the values of serial resistance $R_{s}$ or leakage $R_{s h}$, obviously after a prior filtration of $I-V$ curves, according to the second parameter. This process enables analyses of mechanical and material degradation level of the PV modules.

3. In diagnosing the level of degradation of modules material structure, using only the reduced $I-V$ characteristics of the modules, without translating into STC conditions the presented method is not limited in using $I-V$ characteristics measured above the minimum level of $G_{P O A} \geq 600 \mathrm{~W} / \mathrm{m}^{2}$.

4. Making regular records of $I-V$ characteristics of the modules operating in open space and placing them in a single graph, together with the characteristics recorded directly after the module start up, provides the basic material for analysing the speed and level of degradation of operating modules and assessing their technical condition.

5. Implementing the function for regular (e.g. annual) recording of $I-V$ characteristics of operating PV modules would enable a fast and simple method for performing the basic analysis of their technical conditions on location. Their dismantling and transport to a research laboratory would not be necessary.

The authors hope that the above publication shall contribute to popularizing the research method as a cheap and effective method of estimating usability of modules to operate outdoors. This will allow to intensify research on optimisation of newly created cells and modules to the conditions reflecting actual climatic conditions in specified geographical regions.

\section{References}

[1] Rodziewicz T, Rajfur M, Wacławek M. The use of two-diode substitute model in predicting the efficiency of PV conversion in low solar conditions. Ecol Chem Eng S. 2017;24(2):177-202. DOI: 10.1515/eces-2017-0012.

[2] IEC 60904-3, $2^{\text {nd }}$ edition. Photovoltaic devices - Part 3: Measurement principles for terrestrial photovoltaic (PV) solar devices with reference spectral irradiance data. Geneva: 2008. http://www.iec.ch/dyn/www/f?p=103:23:0::::FSP_ORG_ID:1276.

[3] Coors S, Böhm M. Validation and comparison of curve correction procedures for silicon solar cells. Proc $14^{\text {th }}$ EC PVSEC. Barcelona; 1997:220-223. https://www.eupvsec-proceedings.com/.

[4] Herrmann W, Becker H, Wiesner W. Round Robin Test on Translation Procedures for Measured PV Generator Characteristics. Proc. 14 ${ }^{\text {th }}$ EC PVSEC. Barcelona, 1997. https://www.eupvsec-proceedings.com/.

[5] IEC 60 891, $2^{\text {nd }}$ edition: Photovoltaic devices - Procedures for temperature and irradiance corrections to measured I-V characteristics. Geneva: IEC, 2009-12. https://webstore.iec.ch/publication/3821).

[6] Blaesser G. PV Array Data Translation Procedure. Proc. 13 ${ }^{\text {th }}$ EC PVSEC. Nice 1995:1520-1523. https://www.eupvsec-proceedings.com/.

[7] Anderson AJ. Final Subcontract Report, NREL subcontract No. TAD-4-14166-01, NREL, 1617 Cole Boulevard, Colden, Colorado, January 1996. http://www.nrel.gov/docs/legosti/old/20279.pdf.

[8] Araujo GL, Sanchez E, Marti M. Determination of the two-exponential solar cell equation parameters from empirical data. Solar Cells. 1982;5(2):199-204. http://www.sciencedirect.com/science/journal/03796787/5/2. 
[9] Coors S, Böhm M. Application of the two-exponential model to correction procedure for silicon solar cells. $1^{\text {st }}$ EuroSun. 1996:614-619. https://www.researchgate.net/publication/288667008_Application_of_the_twoexponential_model_to_correction_procedures_for_silicon_solar_cells.

[10] IEC 60 904-10, 2nd edition. Methods of linearity measurement. Geneva: 2006. https://webstore.iec.ch/publication/3873, http://www.iec.ch/dyn/www/f?p=103:23:0::::FSP_ORG_ID:1276 .

[11] Tsuno Y, Hishikawa Y, Kurokawa K. Temperature and irradiance dependence of the I-V curves of various kinds of solar cells. Technical Digest of the PVSEC 15. Shanghai, 2005:422-423. http://www.kurochans.net/paper/15th_PVSEC/pvsec15_tsuno.pdf.

[12] King DL, Kratochvil JA, Boyson WE. Temperature coefficients for PV modules and arrays. Measurement methods, difficulties, and results. Proc $26^{\text {th }}$ IEEE PVSC. Anaheim: 1997. DOI: 10.1109/PVSC.1997.654300.

[13] Virtuani A, Pavanello D, Friesen G. Overview of temperature coefficients of different thin film photovoltaic technologies. Proc 25 ${ }^{\text {th }}$ EU PVSEC. Valencia: 2010:4248-4252. https://www.researchgate.net/profile/ Diego_Pavanello/publication/256080289_Overview_of_Temperature_Coefficients_of_Different_Thin_Film _Photovoltaic_Technologies/links/557eda6d08aeb61eae260cd0/Overview-of-Temperature-Coefficients-ofDifferent-Thin-Film-Photovoltaic-Technologies.pdf.

[14] Marion B, Rummel S, Anderber A. Current-voltage translation by bilinear interpolation. Prog Photovolt. 2004;12:593-607. DOI: 10.1002/pip.551.

[15] IEC 60 904-1. Photovoltaic Devices - Part 1: Measurement of photovoltaic current-voltage characteristics. Geneva: IEC; 1987. http://www.iec.ch/dyn/www/f?p=103:23:0::::FSP_ORG_ID:1276.

[16] Breitenstein O, Bauer J, Altermatt PP, Ramspeck K. Influence of defects on solar cell characteristics. Solid State Phenomena Vols. 2010;156-158:1-10. http://www.scientific.net.

[17] Breitenstein O, Altermatt PP, Ramspeck K, Schenk A. The Origin of Ideality Factors > 2 of Shunts and Surfaces in the Dark I-V Curves of Si Solar Cells. Proc $21^{\text {th }}$ Eur Photovoltaic Solar Energy Conference and Exhibition. Dresden: 2006. http://www-old.mpi-halle.mpg.de/mpi/publi/pdf/7197_06.pdf.

[18] Schenk A, Krumbein U. Coupled Defect - Level Recombination: Theory and Application to Anormalous Diode Characteristics. J Appl Phys. 1995;78:3185. http://aip.scitation.org/doi/abs/10.1063/1.360007.

[19] Queisser HJ. Forward characteristics and efficiencies of silicon solar cells. Solid-State Electronics. 1962;5:1-10. DOI: 10.1016/0038-1101(62)90012-6.

[20] Kaminski A, Marchand JJ, Omari HEl, Laugier A, Le QN, Sarti D. Conduction processes in silicon solar cells. Proc $25^{\text {th }}$ IEEE PVSC. Washington DC: 1996:573-576.

[21] Breitenstein O, Heydenreich J. Non-ideal I-V-characteristics of block-cast silicon solar cells. Solid State Phenomena. 1994;37-38:139. DOI: 10.4028/ www.scientific.net/SSP.37-38.139.

[22] Blaesser G. The reduced current-voltage characteristic of PV arrays and its quasi-independence of ambient conditions. $14^{\text {th }}$ EPSEC. Balcerona: 1997:1520-1523. http://cordis.europa.eu/publication/ren/ 199710913_en.html.

[23] Caamaño-Martín E, Lorenzo E, Lastres C. Crystalline silicon photovoltaic modules: Characterization in the field of rural electrification. Prog Photovolt Res Appl. 2002;10:481-493. DOI: 10.1002/pip.436.

[24] Gueymard C. SMARTS2, a Simple Model of the Atmospheric Radiative Transfer of Sunshine. FSEC-PF-270-95. Florida Solar Energy Centre; ftp://alpha.fsec.ucf.edu/public/smarts2/ or http://homepage.mac.com/cgueymard.

[25] Gray Jeffery L. The Physics of the Solar Cell. Chapter 3. In: Handbook of Photovoltaic Science and Engineering. Luque A, Hegedus S, editors. England: John Wiley \& Sons; 2003.

[26] Hovel HJ. Semiconductors and Semimetals. In: Willardson RK, Beer AC, editors. Solar Cells. New York: Academic Press; 1975. https://www.osti.gov/scitech/biblio/7284142.

[27] Gueymard C. SMARTS code, version 2.9.2, USER'S MANUAL. http://www.astm.org and http://rredc.nrel.gov/solar/models/SMARTS/.

[28] IEC 61853-4 ED1. Photovoltaic (PV) module performance testing and energy rating - Part 4: Standard reference climatic profiles. http://www.iec.ch/dyn/www/f?p=103:23:0::::FSP_ORG_ID:1276, http://www.iec.ch/dyn/www/f?p=103:38:6878505369315::::FSP_ORG_ID,FSP_APEX_PAGE,FSP_PROJE CT_ID:1276,23,22384. 